\title{
Essays On Disaster Management Issues Related To Household Preparedness And Public Attention
}

\author{
By \\ Hanna Habibi
}

\begin{abstract}
A thesis
submitted to the Victoria University of Wellington in fulfilment of the requirements for the degree of Doctor of Philosophy in Economics.
\end{abstract}

Victoria University of Wellington

2020 
To my husband, Karam, for his unconditional love and support... 


\section{ABSTRACT}

This dissertation contains an essay on the effects of earthquake exposure on household preparedness in the short and long term and two essays on the predictors of public attention to earthquakes around the world.

In Chapter I, I use a difference-in-differences method to estimate the causal effects of the 2010 and 2011 Canterbury earthquakes on people's preparedness in the short-term (one month after the second earthquake) and long-term (up to 25 months after the second earthquake). I find that people who experienced the earthquakes increase their preparedness by 0.67 standard deviations in the short term. This impact stays positive but declines to 0.42 standard deviations in the long term.

In chapter II, I investigate whether people from Western countries pay more attention to earthquakes in Western countries. I use Google Trends data and examine the proportion of Google searches from the United States, the United Kingdom, Canada, Australia, and New Zealand for 610 earthquakes across the world over the period of 2006-2016. I find that people in these countries pay on average around 50 percent more attention to earthquakes in Western countries. My results are significant and consistent after controlling for geographical and social characteristics but becomes small and insignificant once I control for GDP per capita of the countries where 
the earthquake struck. There seems to be a developed country bias rather than a Western country bias.

In the final chapter, I measure public attention - using the volume of Google searches - from 18 countries and investigate which factors predict public attention to earthquakes at international level. I focus on 372 earthquakes registered as disasters in The Emergency Events Database (EM-DAT) over the period 2004-2018. I find that people pay more attention to earthquakes in richer countries, in more democratic countries, and in countries with which they have more social and cultural similarities. I also find that social and cultural similarities predict more public attention from Western and Latin American countries and less public attention from Arab and Sub-Saharan African countries. While, the findings of the economic and political status of countries are universal and predict more public attention in all four groups of countries. 


\section{ACKNOWLEDGEMENTS}

I foremost thank my husband, Karam, for being always there for me. I also thank my mother for knowing me better than myself and encouraging me to take this Journey.

I am incredibly grateful to Jan Feld and Ilan Noy for supervising my research and encouraging me to explore different opportunities and pursue diverse research questions. I also thank Ilan Noy and the Resilience National Science Challenge for supporting my PhD through Chair in Economics of Disasters Scholarship. 


\section{DECLARATION}

The results in the second chapter of this thesis are not official statistics. They have been created for research purposes from the Integrated Data Infrastructure (IDI) managed by Statistics New Zealand.

The opinions, findings, recommendations, and conclusions expressed in this chapter are those of the author(s), not Statistics NZ or Victoria University of Wellington.

Access to the anonymized data used in this study was provided by Statistics NZ in accordance with security and confidentiality provisions of the Statistics Act 1975. Only people authorised by the Statistics Act 1975 are allowed to see data about a particular person, household, business, or organisation, and the results in this paper have been confidentialized to protect these groups from identification.

Careful consideration has been given to the privacy, security, and confidentiality issues associated with using administrative and survey data in the IDI. Further detail can be found in the Privacy impact assessment for the Integrated Data Infrastructure available from www.stats.govt.nz. 


\section{Contents}

ABSTRACT ................................................................................................................ iv

ACKNOWLEDGEMENTS .............................................................................. vi

DECLARATION ............................................................................................... vii

LIST OF TABLES ....................................................................................... xi

LIST OF FIGURES ........................................................................................... xii

CHAPTER 1: $\quad$ Preliminaries ........................................14

1.1 Motivation and findings .................................................................. 14

CHAPTER 2: $\quad$ The Effects of Earthquake Exposure on Preparedness in the Short and Long Term: A Differencein-Differences Estimation .......................................................................................17

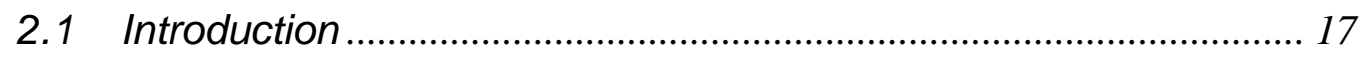

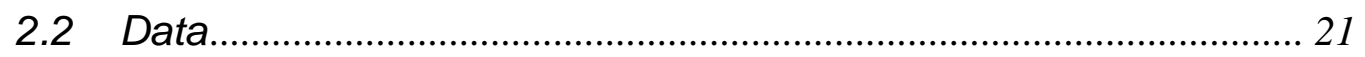

2.2.1 The Canterbury Earthquakes.......................................................... 21

2.2.2 Affected Areas............................................................................... 22

2.2.3 New Zealand General Social Survey ............................................. 23

2.2.4 Sample Restrictions .................................................................... 24

2.2.5 Preparedness Measures and Summary Statistics ……............... 25

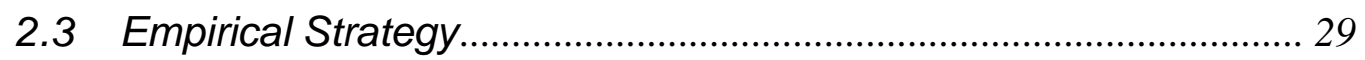

2.3.1 The Econometric Model and Estimation ........................................ 29

2.3.2 Parallel Trends Assumption ........................................................... 32

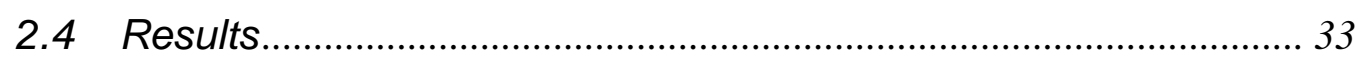

2.4.1 The Effects on Overall Preparedness ........................................... 33

2.4.2 The Effects on Different Dimensions of Preparedness ............... 35

2.4.3 Distinct Preparedness Activities Estimates ................................... 37 


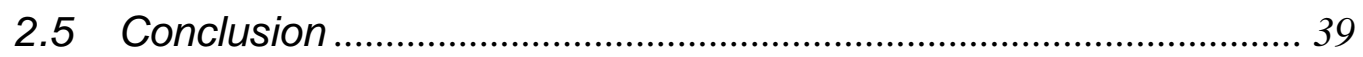

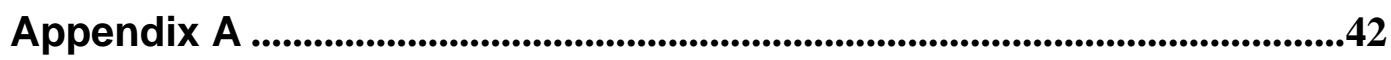

CHAPTER 3: $\quad$ Do People Pay More

Attention to Earthquakes in Western Countries? .....................................46

3.1 Introduction ................................................................................. 46

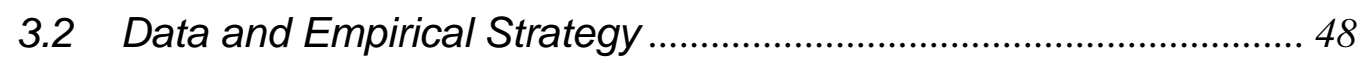

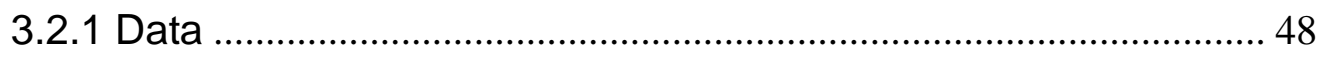

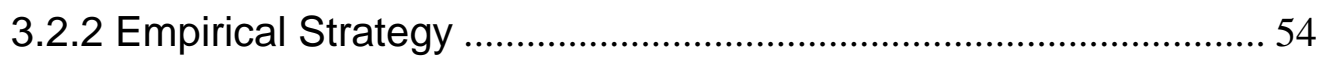

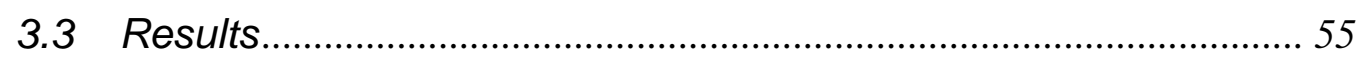

3.4 Conclusion .................................................................................... 57

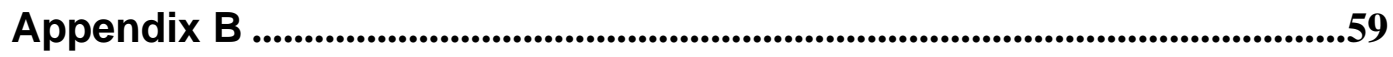

CHAPTER 4: $\quad$ Predictors of International

Public Attention to Disasters: Evidence from 18 Countries....................60

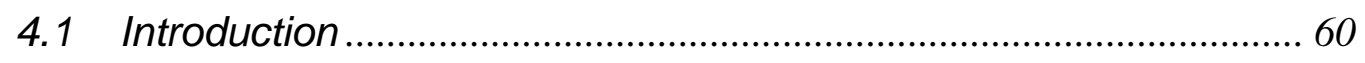

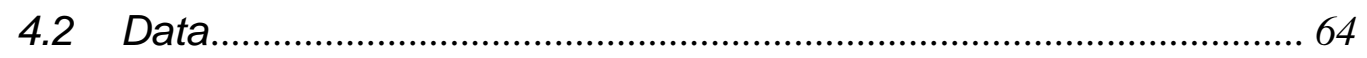

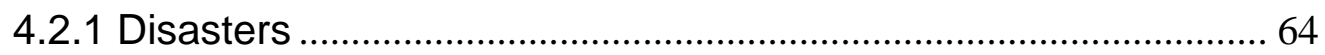

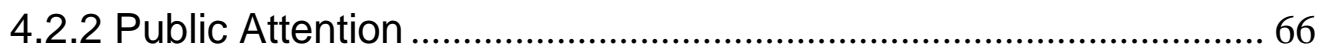

4.2.3 Control Variables ........................................................................... 70

4.2.4 Social and Cultural Factors .......................................................... 72

4.2.5 Economic Factors ...................................................................... 74

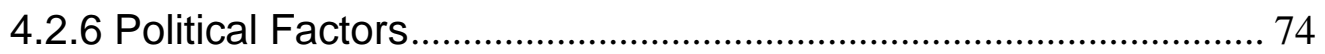

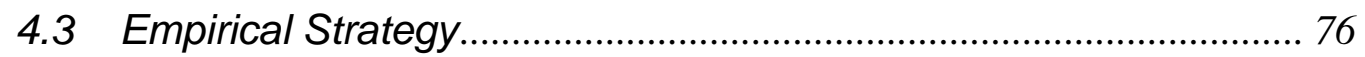

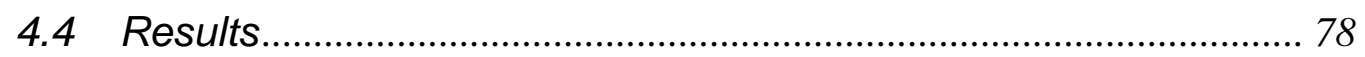

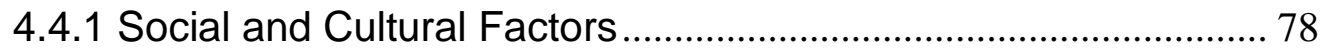

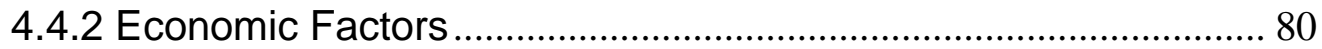

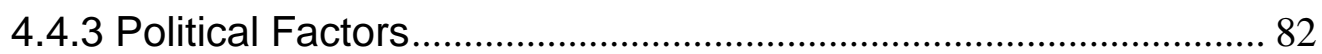




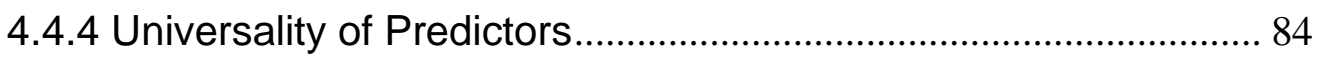

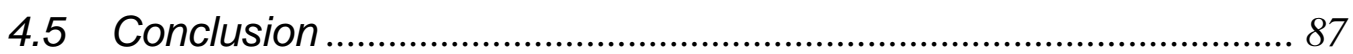

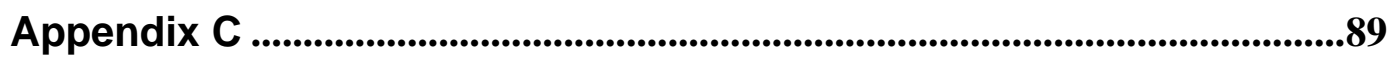

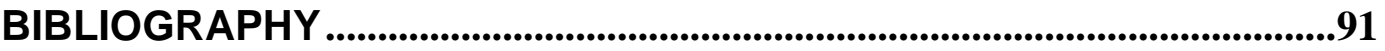




\section{LIST OF TABLES}

Table 2. 1: Questions that Measure Earthquake Preparedness................. 26

Table 2. 2: Descriptive Statistics.................................................................... 29

Table 2. 3: The Impact of Exposure to Earthquakes on Different

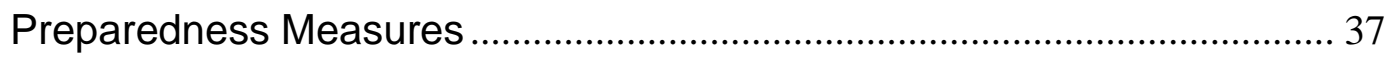

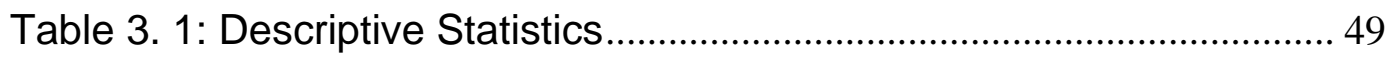

Table 3. 2: Determinants of Public Attention to Earthquakes ..................... 56

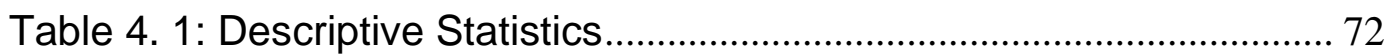

Table 4. 2: Social and Cultural Predictors of International Public Attention

Table 4. 3: Economic Predictors of International Public Attention ............. 81

Table 4. 4: Political Predictors of International Public Attention ................. 83

Table 4. 5: Social and Cultural Similarities, Economic and Political Status

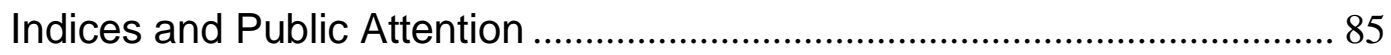

Table A 1: Table of Modified Mercalli Index (MMI) Scale ........................... 42

Table A 2: Comparison of Demographic Characteristics before and after the

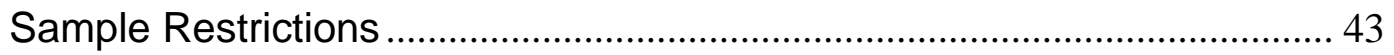

Table A 3: Cronbach's Alpha of the Measure of Preparedness ................ 44

Table A 4: Estimates for Each Preparedness Activity ................................. 45

Table B 1: Western countries separate coefficients .................................. 59 


\section{LIST OF FIGURES}

Figure 2. 1: Identification of Areas Affected by the 2010 Earthquake ....... 23

Figure 2. 2: Timeline of Data Collections and Earthquakes ....................... 24

Figure 2. 3: Distribution of Households' Preparedness............................... 28

Figure 2. 4: Timeline of the Estimation Periods........................................... 31

Figure 2. 5: Trends of Average Household Preparedness in Affected and

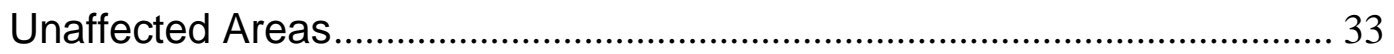

Figure 2. 6: Effects of Earthquake Exposure on Preparedness ................. 34 Figure 2. 7: The Short-Term and Long-Term Effects of Individual

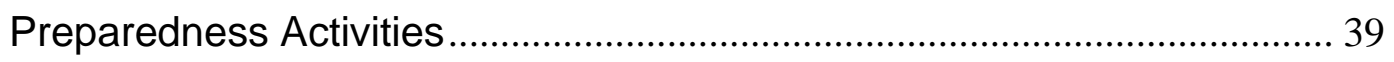

Figure 3. 1: Illustration of Data Extraction from Google Trends ................. 51

Figure 3. 2: Distribution of Public Attention................................................. 52

Figure 3. 3: Coefficient Plot of Western Country Dummies........................ 57

Figure 4. 1: The Map of Countries of Attention ...........................................6 65

Figure 4. 2: Percent of Internet Users in Countries of Attention ................. 67

Figure 4. 3: Illustration of Data Extraction from Google Trends ................. 69

Figure 4. 4: Distribution of Public Attention .................................................. 70

Figure 4. 5: Coefficient Plot of Economic Factors for Countries with Different

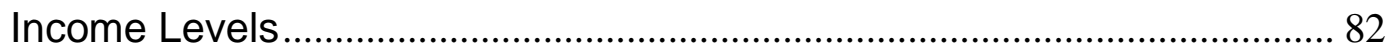

Figure 4. 6: Coefficient Plot of Social and Cultural Similarities, Economic Factors, and Political Status Indices Comparison...................................... 86 
xiii

Figure C 1: Coefficient Plot of Social and Cultural Similarities, Economic and Political Status Indices Comparison 89

Figure C 2: Comparision of the Distribution of Public Attention Variable with Negative Binomial and Poisson Distributions 90 


\section{CHAPTER 1: \\ Preliminaries}

This paper-based thesis consists of three papers. The current chapter briefly explains the motivation and findings of each paper.

\subsection{Motivation and findings}

The first paper is titled "The Effects of Earthquake Exposure on Preparedness in the Short and Long Term: A Difference-in-Differences Estimation". In this paper, we estimate the short-term and long-term impacts of exposure to earthquakes on earthquake preparedness focusing on the Darfield and Christchurch earthquakes that hit New Zealand's Canterbury region in 2010 and 2011. The main motivation to conduct this research is to fill an important gap in the literature by tracking the impact of exposure to earthquakes in long-term. We track the impact of exposure to earthquakes for up to 30 months where the previous literature only tracks the earthquake impacts for up to two and a half months. We further use a large representative sample with preparedness information for over 20,000 New Zealand households, and use measures of pre-earthquake preparedness that were collected before the earthquakes hit. Our findings suggest that exposure to a significant earthquake causes more earthquake preparedness both in the short term (six months after the first earthquake and one month after the second earthquake) and the long term (between 23 to 25 months after the second earthquake). We also find that experiencing earthquakes has the most effect on water storage and emergency planning in the short and the long term.

The second paper is titled "Do People Pay More Attention to Earthquakes in Western Countries?". In this paper, we examine whether people from Western countries pay more attention to earthquakes in Western countries. 
We measure public attention using the volume of Google searches on the keywords related to earthquakes from internet users of the United States, the United Kingdom, Canada, Australia, and New Zealand to 610 significant earthquakes across the world from 2006-2016. The motivation behind this study is the anecdotal evidence that suggest people from Western countries pay more attention to critical events in Western countries. By measuring people's search activities, we are the first to examine explicitly whether people as opposed to the media in Western countries pay more attention to earthquakes in Western countries. A main contribution of this paper is measuring attention from people directly rather that measuring media attention. We argue that factors such as limited number of reporters in the country of earthquake or simultaneous media events like Olympics might influence media attention and the events that grab people's attention nowadays are not limited to those that are covered in media. Holding constant earthquake severity, we find that earthquakes in Western countries receive more attention from other Western countries. However, this correlation reduces in magnitude and becomes insignificant after controlling for countries GDP per capita, suggesting that this apparent Western Bias can be driven by Western countries' stronger economic power.

The last paper is titled "Predictors of International Public Attention to Disasters: Evidence from 18 Countries". In this study we examine which factors predict how much public attention earthquakes receive at international level. We measure public attention from a wider range of countries considering two objectives; first, having enough variation with regards to countries' social and cultural, economic, and political backgrounds, and second, being able to break them into distinguishable groups for further analysis. Our motivations to conduct this research are i) to provide a comprehensive analysis on the predictors of public attention and uncover a wider range of predictors than the earlier studies and ii) to 
examine the universality of these predictors. Previous studies focus on predictors of public attention from Western countries only, and we do not know if these findings genialize. To address this gap, we break the countries from which we measure public attention into four groups of countries and compare the findings for these groups to show which predictors are universal. We show that countries' social and cultural, economic, and political factors predict the public attention they receive from other countries. Among these predictors, economic factors and political status of countries are universal, while social and cultural similarities predict public attention in different directions for different sub-samples and therefore cannot be considered as universal predictors of public attention. 


\section{CHAPTER 2: \\ The Effects of Earthquake Exposure on Preparedness in the Short and Long Term: A Difference-in-Differences Estimation}

\subsection{Introduction}

Disasters triggered by natural hazards like floods and earthquakes have serious consequences. They damage properties, injure and kill people, and affect households by causing disruption in roads and utility networks. Since emergency support is often delayed, it is important that households are sufficiently prepared to deal with the immediate aftermaths of disasters.

Emergency management officials promote self-efficiency to cope with disasters by specifying which supplies to buy and which actions to take (Russell et al., 1995). The Red Cross (2019) identifies well-prepared households to be those who understand disasters and their effects, have a household survival plan, assemble and maintain emergency items, and have a getaway kit/bag. Despite of the importance of being prepared, few people prepare effectively. Only $25 \%$ of Americans have adequate emergency plans and all recommended emergency items (Petkova et al., 2016). Similarly, only 14\% of New Zealanders are fully prepared (Disaster Preparedness Survey, 2016).

Underpreparedness for disasters could be the result of optimism bias (McClure, 2006). This cognitive bias occurs when people believe they are less likely to experience disasters than the average person. Experiencing disasters can mitigate optimism bias and cause people to be more prepared (Rogers, 1983; Mulilis et al., 1990; Russell et al., 1995; Mulilis et al., 2003; Nguyen et al., 2006; Lindell and Perry, 2000). However, it can also cause 
people to be less prepared if they survived a natural disaster without harm (Johnston et al., 1999; Paton et al., 2014). Moreover, people tend to forget the lessons of past disasters, which suggests they would return to their predisaster preparedness level (Mulilis et al., 1990; Meyer \& Kunreuther, 2017). Yet, we do not know how long this would take.

In this paper, we estimate the short-term and long-term impacts of exposure to significant earthquakes on earthquake preparedness. We focus on the effect of the Darfield and Christchurch earthquakes that hit New Zealand's Canterbury region in 2010 and 2011. To identify the areas affected by these earthquakes, we use data on ground shaking from the United States Geological Survey (USGS) and data on geographical boundaries from Statistics New Zealand. We measure households' preparedness using eleven questions about within-building preparedness activities available in the New Zealand General Social Survey (NZGSS). ${ }^{1}$ This repeated crosssectional survey provides us with preparedness data for 30 months before the earthquakes and 30 months after the earthquakes. We further conduct an in-depth analysis on the components of our preparedness measure, such as storing water and food, to find which preparedness activities were most affected by the earthquakes.

To estimate the short-term and long-term effects of exposure to major earthquakes on preparedness, we employ a difference-in-difference approach (Ashenfelter and Card, 1984). Using this approach, we test how the differences in preparedness of affected and unaffected areas change after the earthquakes. Differences between these areas before the

${ }^{1}$ Our measure does not include building-structure preparedness such as adherence to building codes. 
earthquakes are due to factors unrelated to the earthquakes, and differences after the earthquakes are due to the unrelated factors as well as exposure to the earthquakes. Assuming the same pre-earthquake differences exist after the earthquake, we can subtract them from the postearthquake differences and get an unbiased estimate of the causal impact of earthquake exposure on preparedness.

Our findings show that earthquake exposure causes more earthquake preparedness both in the short term and the long term. In the short term (six months after the first earthquake and one month after the second earthquake), the earthquakes cause a 0.67 standard deviations increase in preparedness. In the long term, the impact stabilises at 0.54 standard deviations (between 13 to 22 months after the second earthquake) and then decreases but remains positive at 0.46 standard deviations (between 23 to 25 months after the second earthquake). Looking into preparedness activities separately shows that experiencing earthquakes has the most effect on water storage and emergency planning in the short and the long term.

Several studies find that previous experience of earthquakes and preparedness are positively correlated (Onuma et al., 2017; Becker et al., 2017; Hoffmann \& Muttarak, 2015; and Kirschenbaum et al., 2017; Goeschl \& Managi, 2019). However, this relationship might not be causal as higher preparedness after an earthquake in affected areas could be due to other factors. If this were the case, we would expect households in affected areas to be more prepared even before an earthquake hits. Two studies take this source of bias into account by controlling for pre-earthquake preparedness when estimating the causal effects of earthquake exposure on preparedness. Russell et al. (1995) investigate the determinants of households' earthquake preparedness after the Whittier Narrows and Loma 
Prieta earthquakes. They do this by regressing household preparedness on exposure to earthquakes and several other independent variables, controlling for pre-earthquake preparedness. They categorize preparedness activities into survival, preparedness planning, and hazard mitigation, and they only find higher preparedness planning among those who experienced Whittier Narrows earthquake. Nguyen et al. (2006) regress preparedness on exposure to the Northridge earthquake and a number of other explanatory variables, controlling for pre-earthquake preparedness. Their results show that households exposed to high earthquake intensity are more prepared for earthquakes compared to households exposed to moderate intensities. Both of these studies rely on pre-earthquake preparedness measures that were self-reported and collected months after the earthquakes hit. Data on pre-earthquake preparedness collected after earthquakes hit is less reliable as people might not precisely remember how prepared they were.

Only one study examines the short-term impact of earthquake exposure on preparedness by using pre-earthquake preparedness data that was collected before the earthquake. Mulilis et al. (1990) survey undergraduate students three weeks before the Whittier Narrows earthquake and continue their survey for two-and-a-half months after the earthquake hit. They divide their respondents into two main groups. Group one continues to complete the survey regularly after the earthquake, and group two completes the survey less frequently throughout the semester. Their results show an initial increase in earthquake preparedness in both groups. After two-and-a-half months, group one stays prepared and group two returns to its preearthquake preparedness level. The authors argue that their findings are mainly a result of the impact of receiving the survey regularly. These findings suggest that the impact of exposure to an earthquake disappears 
shortly after the earthquake unless people are regularly reminded to be prepared.

Our paper makes three contributions to the literature. First, we estimate the causal impact of exposure to earthquakes on households' preparedness using a large, representative sample and high-quality measures of preearthquake preparedness. Our sample includes preparedness information for over 20,000 New Zealand households, and we have measures of preearthquake preparedness that were collected before the earthquakes hit. Second, we track the impact of exposure to earthquakes for up to 30 months. In contrast, the previous literature only tracks it for up to two-and-a-half months. Third, we look at each preparedness activity separately, which allows us to show which of them people adjust after the earthquake.

\subsection{Data}

\subsubsection{The Canterbury Earthquakes}

Two major earthquakes hit New Zealand's Canterbury region in 2010 and 2011. The first one had a magnitude of 7.1 and hit on 4 September 2010 at 4:35am. This earthquake caused widespread damage and disruption to water, power, and sewerage services, but no loss of life. The second earthquake had a magnitude of 6.3 and hit on 22 February 2011 at $12: 51 \mathrm{pm}$. It killed 185 people and caused major damage to Canterbury land, buildings, and infrastructure (Potter et al., 2015; Kongar at al., 2017). One day after this earthquake, the Ministry of Civil Defence declared a state of National Emergency for the second time in New Zealand's history. The population of the Canterbury region in 2013 census was 539,436 , which is equal to $12.7 \%$ of the country's population (Statistics New Zealand, 2013). The total economic losses of these earthquakes are estimated to be more than NZ $\$ 40$ billion (Wood et al., 2016). 


\subsubsection{Affected Areas}

We identify the areas affected by the Canterbury earthquakes by overlaying a map of New Zealand geographic boundaries and a map of the earthquake intensity as shown in Figure 2.1. To distinguish precisely which areas were affected, we divide the country into small geographic units using New Zealand's map of area unit boundaries (Statistics New Zealand, 2013). An area unit is the second smallest geographic unit available for New Zealand. On average, 2,000 people live in an area unit (Statistics New Zealand, 2017). To measure earthquake intensity, we use the Modified Mercalli Index (MMI) data from the USGS ShakeMap (U.S. Geological Survey, 2018). The MMI is a seismic intensity scale that measures the intensity of ground motions both from structural response and people's perspective (see Table A1 in Appendix for more detailed information on the MMI). We classify areas as affected if they lived in an area that had an MMI score of 3 and above. 
Figure 2. 1: IDENTIFICATION OF AREAS AfFected by the 2010 EARTHQUaKe

Legend

Unaffected Area Units

Affected Area Units

Earthquake Intensity

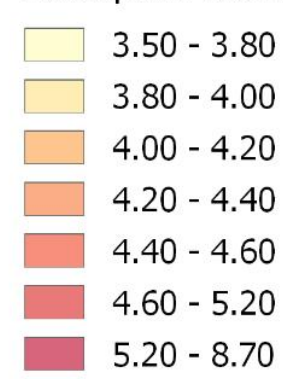

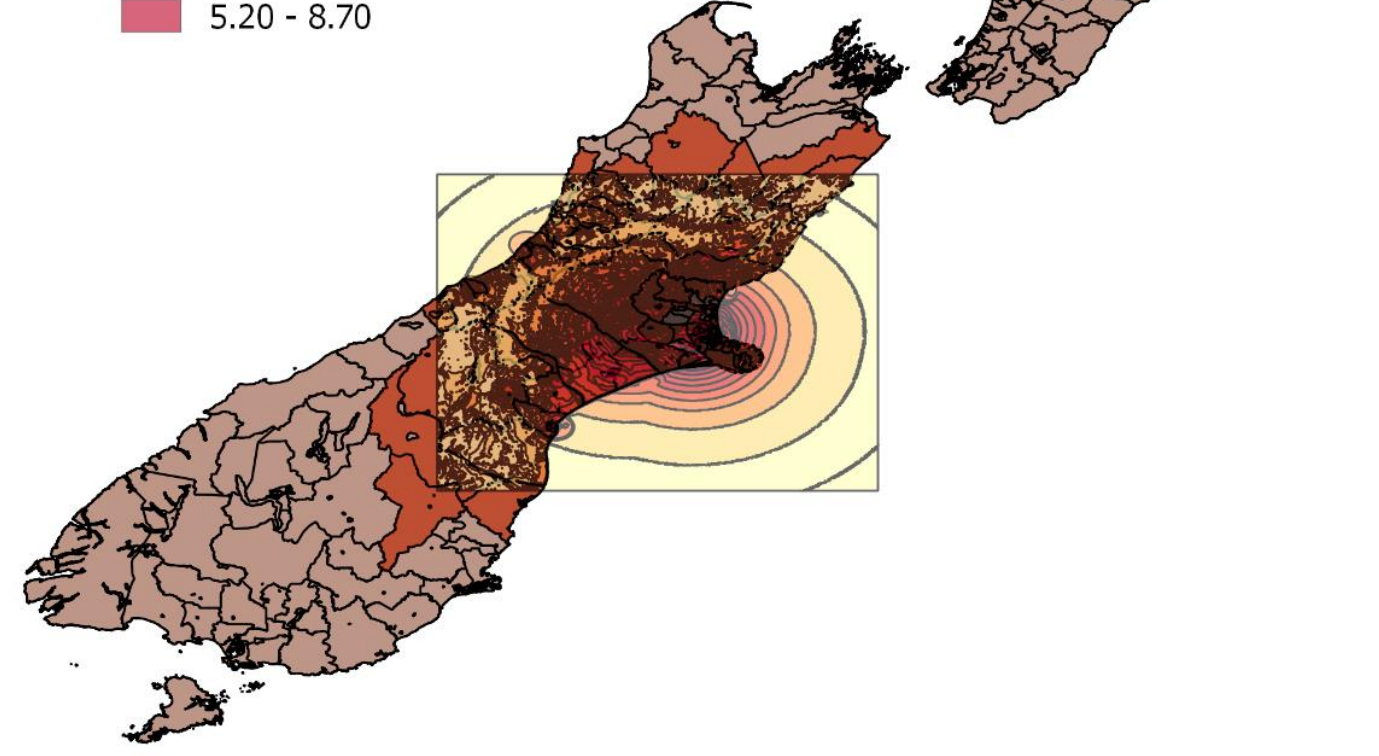

NOTE: In this map, we overlay the USGS ShakeMap (it appears here as a square) and the map of New Zealand's area unit boundaries. The darker areas on the map show the affected area units. The coloured intensity intervals are based on 0.2 intensity units. This map shows the intensity of the first earthquake. The areas affected by the two earthquakes are almost identical except for a few areas that were not affected by the second earthquake.

\subsubsection{New Zealand General Social Survey}

We obtain information about the people living in the affected and unaffected areas from the NZGSS. This survey is run every two years since 2008 by Statistics New Zealand (Statistics New Zealand, 2019). It is collected using 
a multistage sample design by first randomly selecting the households and then randomly selecting one person aged 15 and over within the household to answer the questionnaires. The NZGSS personal questionnaires maintain participants' anonymity while providing us with the date of households' participation in the survey, information on the households' socioeconomic status, and the households' location within New Zealand's geographic boundaries. We combine the data from the NZGSS 2008, 2010, and 2012 with information from 8,721, 8,550, and 8,462 personal questionnaires which provide us with preparedness information for 25,733 households.

These surveys include data collected in three twelve-month periods that range from April 2008 to March 2013. Figure 2.2 shows the timeline of the data collection in relation to the earthquakes. Our data consists of a long pre-earthquake period. This allows us to identify pre-existing differences in preparedness among the households in affected and unaffected areas. We also have data for a long post-earthquake period, and this allows us to identify the earthquakes' short-term and long-term impacts.

Figure 2. 2: TIMELINE OF DATA COLLECTIONS AND EARTHQUAKES

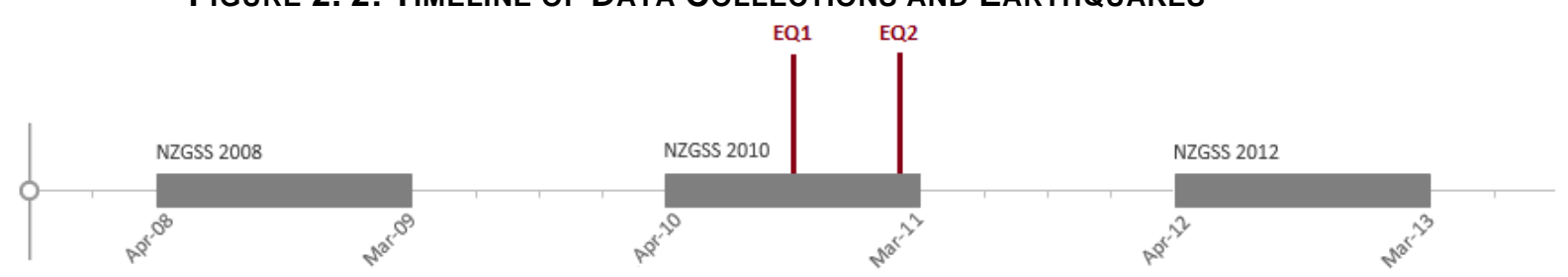

\subsubsection{Sample Restrictions}

We make two sample restrictions to ensure we are strictly comparing affected and unaffected households. First, we exclude households who changed their location before and after the earthquakes from the affected areas into unaffected areas or vice versa. We identify households' locations before and after the earthquakes using Address Notification dataset from 
Statistics New Zealand. This dataset keeps track of people's location over time by recording their addresses whenever they provide them to public sector organizations such as universities and the internal revenue department. Second, we exclude households that we classified as unaffected but experienced the 7.8 magnitude Fiordland earthquake that hit the Southland region in 2009. Although this earthquake caused only minor damage and no injuries or fatalities, by excluding households that experienced it, we avoid including people with previous experience of a large earthquake among the "unaffected" households. We also exclude households for which we do not have data on preparedness or demographic characteristics we use as control variables. These restrictions leave us with data from 20,148 households out of 25,733 households. The restricted sample looks virtually identical to the unrestricted sample in terms of demographic characteristics (see Table A2 in Appendix).

Apart from the sample restrictions we made, Statistics New Zealand excluded residents from the Red Zone from the NZGSS 2012 due to earthquake disruptions. The Red Zone, located in the centre of Christchurch, is the area most affected by the second earthquake (Saunders \& Becker, 2015). Within this zone, the properties were not economic to repair or strengthen.

\subsubsection{Preparedness Measures and Summary Statistics}

To measure earthquake preparedness, we combine the responses to 11 questions from the Physical Environment subsection of NZGSS (Statistics New Zealand, 2019). These questions are broadly comparable with, yet more limited than, various measures of preparedness that either replicate or are based on Turner et al. (1986) list of preparedness activities (Russell et al., 1995; Nguyen et al., 2006; Spittal et al., 2008). Table 2.1 shows these questions, which measure households' emergency preparedness and are 
also comparable with the New Zealand's Ministry of Defence and Red Cross definition of preparedness for disasters (Ministry of Civil Defence, 2018; Red Cross, 2019). Similar to Russell et al. (1995), we divide these 11 questions into three categories based on the dimension of preparedness they measure. These categories are Emergency Items, Hazard Mitigation, and Emergency Planning. Before the earthquakes, people were less prepared for activities that require more effort. For example, while only $28 \%$ of households had an emergency plan before the earthquakes, $98 \%$ had a can opener.

Table 2. 1: Questions that Measure Earthquake Preparedness

\begin{tabular}{l|c}
\hline Questions on Preparedness Activities & $\begin{array}{c}\text { Share of "yes" } \\
\text { Answers Before } \\
\text { the Earthquakes }\end{array}$ \\
\hline Emergency Items & 0.411 \\
Does your household have water for three days? & 0.877 \\
Does your household have food for three days? & 0.977 \\
Does your household have a can opener? & 0.399 \\
Does your household have face or dust masks? & 0.917 \\
Does your household have a torch? & 0.670 \\
\hline Does your household have a portable radio? & 0.692 \\
\hline Does your household have spare batteries? & 0.806 \\
\hline Does your household have a first aid kit and essential medicines? & \\
Hazard Mitigation & 0.283 \\
Does your household have heavy and tall furniture that is secured? & 0.741 \\
Does your household have a hot water cylinder that is secured? & \\
\hline Emergency Planning & 0.276 \\
\hline Does your household have a household emergency plan? & \\
\hline
\end{tabular}

NOTE: The questions are available in the Physical Environment category of the NZGSS in 2008, 2010, and 2012.

To answer the questions measuring preparedness, households could choose "yes", "no", "don't know", and "refused". We only allow for "yes" and "no" answers, and treat "don't know" and "refused" answers as missing 
values. To generate our measure of preparedness, we count the number of yes answers. The Cronbach's alpha for our measure of preparedness is 0.66 , which suggests an adequate reliability (see Table $A 3$ in the Appendix). For the questions related to securing furniture and hot water cylinders, households could additionally choose "not applicable". We treat "not applicable" answers as missing values when estimating Hazard Mitigation sub-scale because it only includes the questions on securing furniture and hot water cylinder. A total of 4,230 households provided "not applicable" answers to the questions on securing furniture or/and hot water cylinder. To avoid losing these households when estimating effects on overall preparedness, we calculate their overall preparedness measures based on fewer questions (9 or 10 instead of 11 for the remaining sample) and harmonise these measures to follow the same 12-point scale (from 0 to 11). ${ }^{2}$

Figure 2.3 shows the distribution of our overall measure of preparedness.

\footnotetext{
2 To harmonize, we multiply the score of the households with "not applicable" answers $\left(S_{n a}\right)$ with 11 (the upper bound of the 12-point scale) and divide the result by the number of questions that were applicable $\left(Q_{a}\right)$. For example, a household with nine "yes", one "no", and one "not applicable" answers has 10 applicable questions. Therefore, we calculate its preparedness score as $\frac{\left(S_{n a^{*}} * 1\right)}{Q_{a}}=\frac{9 * 11}{10}=9.9$.
} 


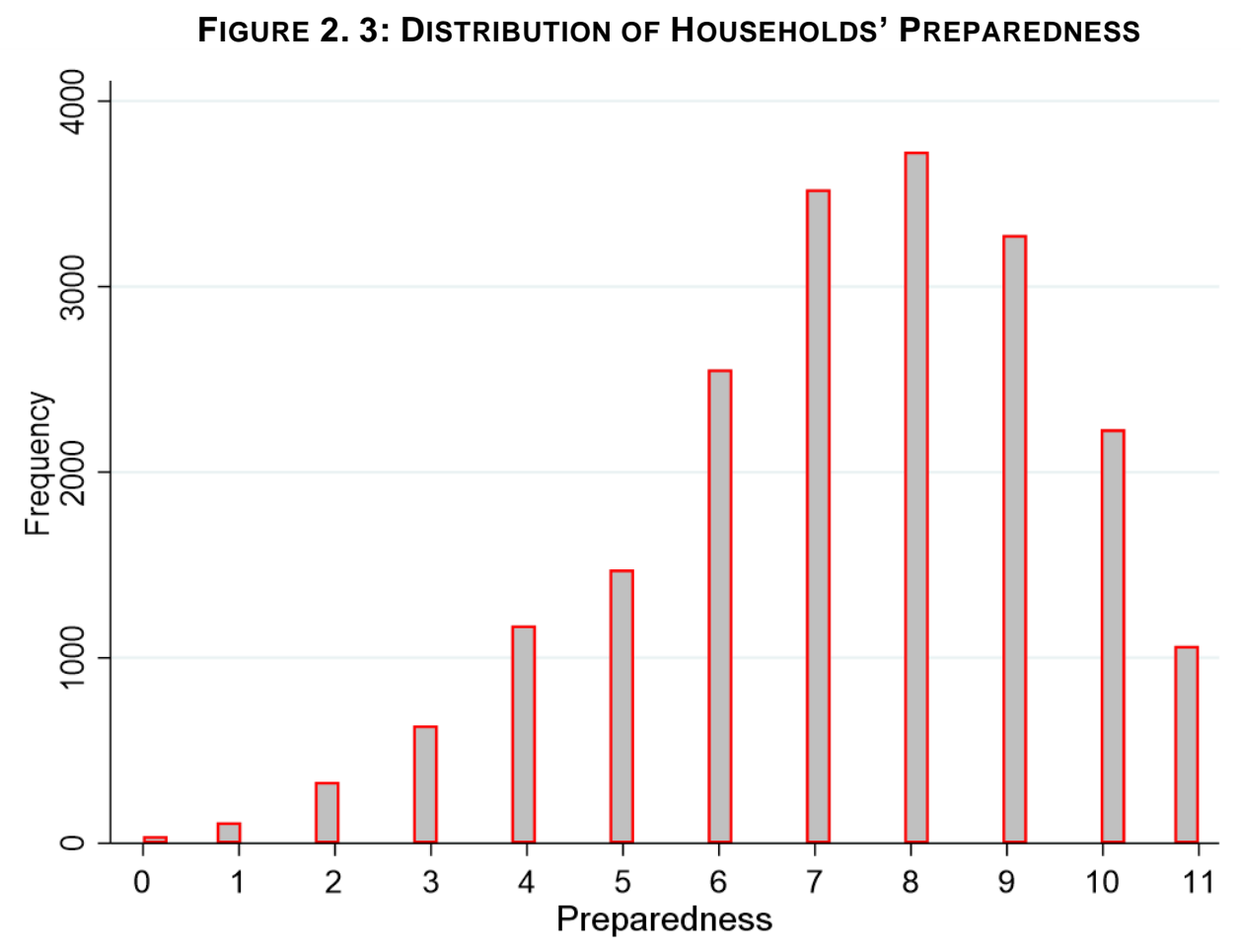

NOTE: Preparedness is measured on a 12-point scale with increasing preparedness actions from $0-11$. We round the harmonized numbers to the next integer. We use the actual numbers in our analysis.

Table 2.2 shows the summary statistics of our main variables and the demographic variables we control for in our analysis. Our overall measure of preparedness has a mean of 7.31 and a standard deviation of 2.15. New Zealand households have on average 5.9 items out of the 8 emergency items, they have done 1.1 out of the 2 hazard mitigation activities, and only $32 \%$ have an emergency plan. Households living in the areas affected by the earthquakes amount to $15 \%$ of the total number of households. Our sample consists of $75 \%$ households of European decent and $7 \%$ Māori. The remaining of households are Asian, Pasifika, other ethnicities, people with dual ethnicities, and missing ethnicities. More than $75 \%$ of the survey respondents were born in New Zealand, 55\% are female, and the average age of respondents is 49 years. 
TABLe 2. 2: Descriptive Statistics

\begin{tabular}{|c|c|c|c|c|c|}
\hline & $\begin{array}{l}(1) \\
\mathrm{N}\end{array}$ & $\begin{array}{c}(2) \\
\text { Mean }\end{array}$ & $\begin{array}{l}\text { (3) } \\
\text { SD }\end{array}$ & $\begin{array}{c}(4) \\
\text { Min }\end{array}$ & $\begin{array}{c}\text { (5) } \\
\text { Max }\end{array}$ \\
\hline Preparedness & 20,148 & 7.31 & 2.15 & 0 & 11 \\
\hline Emergency Items & 20,148 & 5.86 & 1.70 & 0 & 8 \\
\hline Hazard Mitigation & 15,918 & 1.08 & 0.67 & 0 & 2 \\
\hline Emergency Plan & 20,148 & 0.32 & 0.47 & 0 & 1 \\
\hline After Earthquake & 20,148 & 0.50 & 0.50 & 0 & 1 \\
\hline Affected Area & 20,148 & 0.15 & 0.36 & 0 & 1 \\
\hline \multicolumn{6}{|l|}{ Ethnicity } \\
\hline European & 20,148 & 0.75 & 0.43 & 0 & 1 \\
\hline Māori & 20,148 & 0.07 & 0.25 & 0 & 1 \\
\hline Pasifika & 20,148 & 0.03 & 0.18 & 0 & 1 \\
\hline Asian & 20,148 & 0.06 & 0.24 & 0 & 1 \\
\hline Other Ethnicities & 20,148 & 0.03 & 0.16 & 0 & 1 \\
\hline Dual Ethnicity & 20,148 & 0.06 & 0.24 & 0 & 1 \\
\hline Missing Ethnicities & 20,148 & 0.001 & 0.03 & 0 & 1 \\
\hline Born in New Zealand & 20,148 & 0.77 & 0.42 & 0 & 1 \\
\hline Female & 20,148 & 0.55 & 0.50 & 0 & 1 \\
\hline Age & 20,148 & 48.97 & 18.42 & 15 & 99 \\
\hline
\end{tabular}

NOTE: All numbers are based on our estimation sample. 'SD' refers to the standard deviation of the respective variable.

\subsection{Empirical Strategy}

\subsubsection{The Econometric Model and Estimation}

We use a difference-in-difference method to estimate the short-term and long-term effects of exposure to major earthquakes on preparedness. Difference-in-differences is a popular quasi-experimental approach used to estimate causal effects (Lee \& Kang, 2006). A difference-in-differences estimate requires a comparison between the preparedness of the affected and unaffected households before and after the earthquakes. The difference in households' preparedness before the earthquakes is due to factors other than exposure to the earthquakes, and the differences in 
preparedness after the earthquakes are due to experiencing the earthquakes as well as other factors. By subtracting the pre-earthquake differences from the post-earthquake differences, the difference-indifferences method cancels out the differences that were due to other factors and isolates the causal effect of the earthquakes on preparedness. ${ }^{3}$

While the basic difference-in-differences method compares two groups in two periods, we use a more complex method which compares two groups over multiple periods (Callaway \& Sant'Anna, 2019). This method allows us to track how exposure to earthquakes affects household preparedness in different time intervals. It also allows us to estimate the short-term and longterm effects on preparedness. We divide our data into 13 periods (see Figure 2.4). The first period starts 30 months before the first earthquake, and period 13 ends 30 months after it. All periods are three months long except for periods 8 and 9 . Period 8 is two months long and ends just before the second earthquake. Period 9 is one month long and captures the shortterm impact of both earthquakes one month after the second earthquake.

\footnotetext{
3 The approach of difference-in-differences models is similar to the approach of fixed effects models. Both approaches exploit changes over time to difference out time constant factors. The key difference, however, is that fixed effects models require panel data and exploit changes at the individual level. In contrast, difference-in-differences models can be used with cross sectional data and exploit changes at the group level.
} 
Figure 2. 4: Timeline of the Estimation Periods

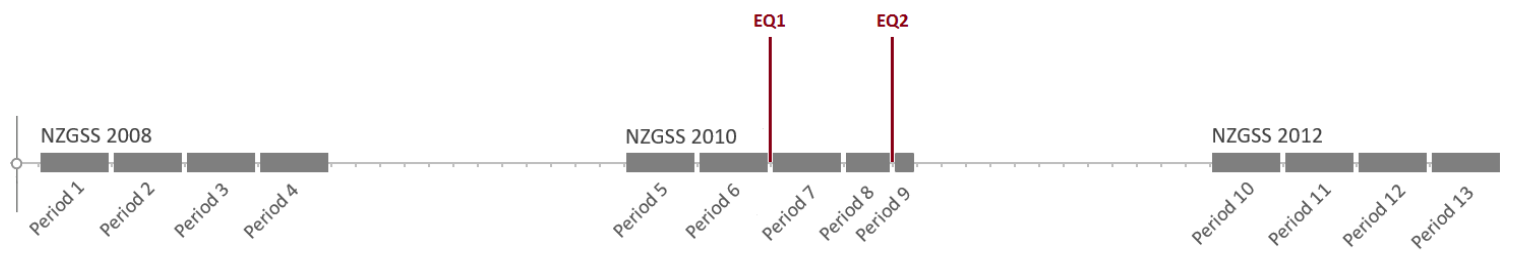

Using the model below, we estimate the effects of exposure to the Canterbury earthquakes on household preparedness in different periods:

Preparedness $_{i a t}$

$$
\begin{aligned}
& =\alpha \text { Afected }_{i a}+\sum_{t=2}^{13} \boldsymbol{\beta} \text { Period }_{t} \\
& +\sum_{t=7}^{13} \gamma\left(\text { Affected }_{i a} \times \text { Period }_{t}\right)+\boldsymbol{\delta} X_{\text {iat }}^{\prime} \\
& +u_{\text {iat }},
\end{aligned}
$$

where Preparedness iat $_{\text {in }}$ is the earthquake preparedness of household $i$, in area $a$, at period $t$. Affected ia $_{i a}$ is a dummy variable equal to one if the household lives in areas affected by the earthquakes. $\sum$ Period $_{t}$ are 12 time dummies ranging from period 2 until period 13 (leaving the first period as our base). $\sum\left(\right.$ Affected $_{i a} \times$ Period $\left._{t}\right)$ are the interaction terms of affected households and periods 7 to 13 (the post-earthquake periods). These interaction terms capture the impact of living in the affected areas on preparedness. The coefficients of interest are $\gamma_{7}, \gamma_{8}, \ldots, \gamma_{13}$, which show the causal effect of exposure to earthquake on preparedness at periods 7 to 13 . For example, $\gamma_{7}$ captures the impact of exposure to the first earthquake on preparedness in period 7 . The vector $X_{\text {iat }}^{\prime}$ includes our control variables age, age squared and dummies for survey respondents' ethnicities, gender, and 
whether they were born in New Zealand. $u_{\text {iat }}$ is the household-specific error term.

We estimate Equation 2.1 using ordinary least squares regressions. The coefficients $\hat{\gamma}_{7}, \hat{\gamma}_{8}, \ldots, \hat{\gamma}_{13}$ show the differences between the affected and unaffected households after the earthquakes at periods 7 to 13 minus the difference between these two types of households before the earthquakes in periods 1 to 6 (holding our control variables constant). For instance, $\hat{\gamma}_{7}$ is our estimate of the causal effect of earthquake exposure in the first three months after the first earthquake. $\hat{\gamma}_{7}$ shows the difference between affected and unaffected households in period 7 minus the difference between affected and unaffected households in periods 1 to 6 .

To make the interpretation of our results easier, we standardize our measures of overall preparedness, Emergency Items, and Hazard Mitigation. After this standardization, these measures have means of zero and standard deviations of one for all periods before the first earthquake hit. Our coefficients in estimations using these measures show standard deviation changes compared to pre-earthquakes levels. The only measure we do not standardize is Emergency Planning, which we leave as a binary variable. Since the preparedness measures are cumulative, we might overestimate t-statistics and significance levels of the difference-indifferences coefficients due to serial correlation (Bertrand et al., 2004). To avoid this problem, we cluster our standard errors at area level.

\subsubsection{Parallel Trends Assumption}

The key assumption to get unbiased difference-in-differences estimates is that the two groups we compare would have followed a parallel trend after the earthquakes in the absence of an earthquake. As evidence that this assumption is likely to hold, Figure 2.5 shows that the affected and unaffected households' preparedness followed parallel trends before the 
first earthquake hit. The divergence after the earthquakes foreshadows the causal effects of the earthquakes on preparedness we show in the next section.

Figure 2. 5: Trends of Average Household Preparedness in Affected and UnAFFeCted AREAS

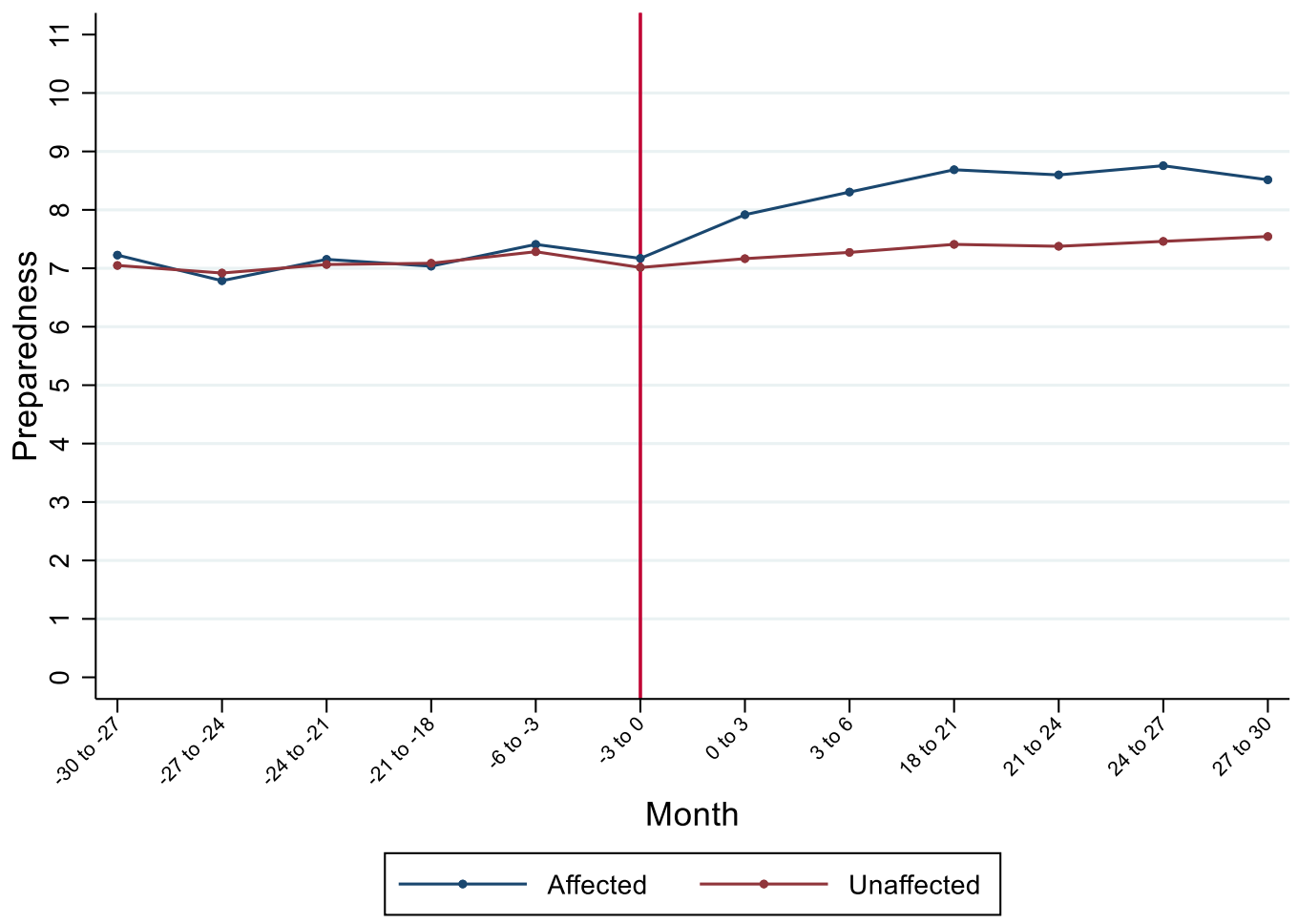

NOTE: The numbers on the $\mathrm{X}$-axis show the months relative to the first Canterbury earthquake (shown in the vertical line). For example, "-30 to -27" refers to a three-month period starting 30 months before the first Canterbury earthquake.

\subsection{Results}

\subsubsection{The Effects on Overall Preparedness}

Figure 2.6 shows the impact of exposure to the Canterbury earthquakes on household preparedness at different periods. Exposure to the earthquakes affects household preparedness positively and significantly both in the short 
and long term. Our results show an impact of 0.32 standard deviations on household preparedness in period 7 . This impact increases to 0.40 standard deviations in period 8 . In these two periods, the affected households were exposed to the first earthquake only.

Figure 2. 6: Effects of EARThQuake Exposure on Preparedness

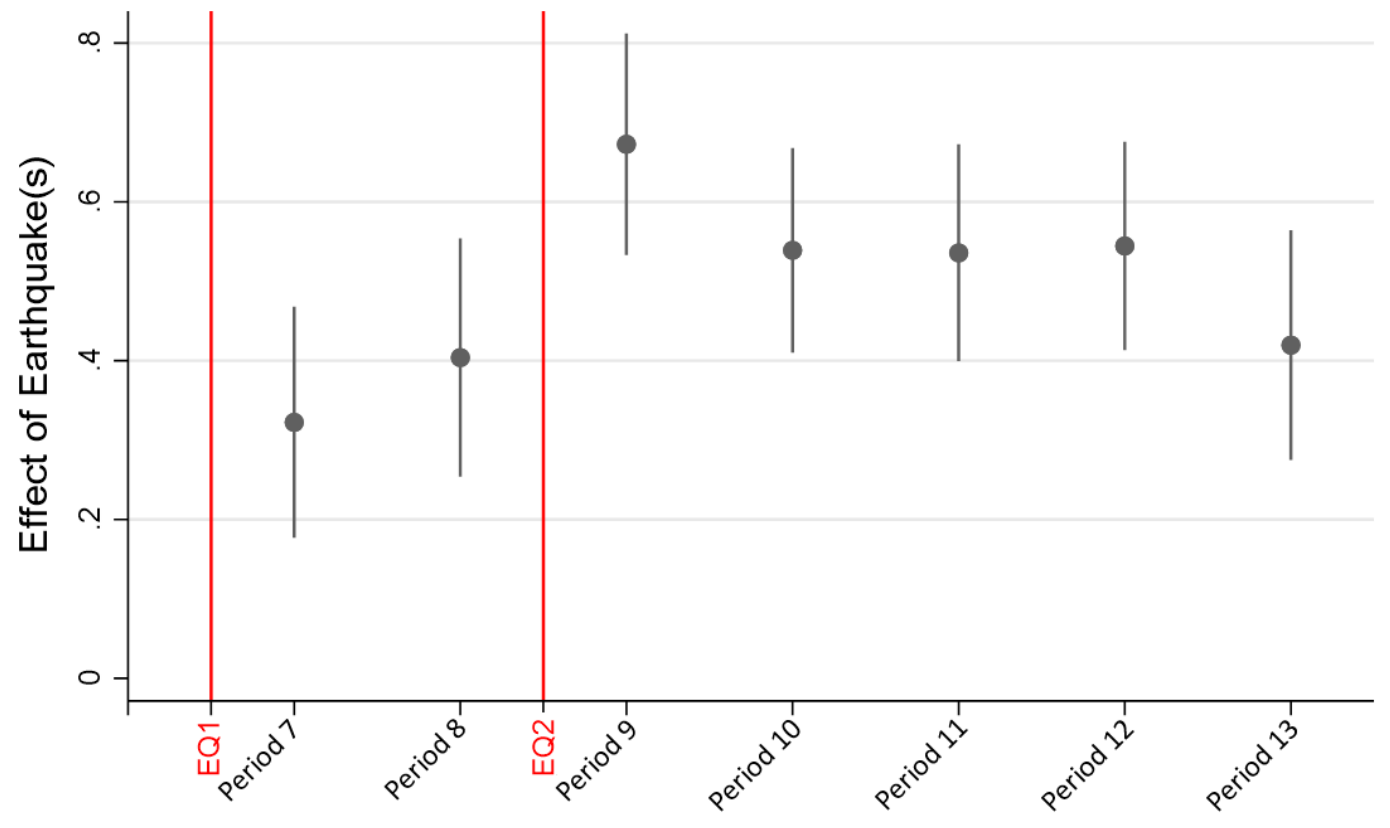

Period

NOTE: The red vertical lines refer to the first and second Canterbury earthquakes. See Column 1 of Table 2.3 for point estimates. The coefficients and their $95 \%$ confidence intervals are based on standard errors clustered at the area level.

When comparing the short-term and long-term impact of earthquake exposure, we focus on comparing the impacts in periods 9 to 13 . In these periods, affected households experienced the same number of earthquakes (two), but we observe their preparedness at different times since the earthquakes hit. In the short term in period 9 (one month after the second earthquake), earthquake exposure increased household preparedness by 0.67 standard deviations compared to pre-earthquake levels. This effect represents an increase of 1.43 out of 11 activities. In the long term (one and 
a half years after the earthquakes), the positive impact on household preparedness stabilizes at 0.54 standard deviations for 9 months. This impact starts to decline yet remains positive at 0.42 standard deviations ( 0.89 out of 11 activities) 27 months after the earthquakes.

\subsubsection{The Effects on Different Dimensions of Preparedness}

To see how exposure to earthquake affects the different dimension of preparedness, we estimate their effects on three preparedness sub-scales. Table 2.3 shows our main estimates (in Column 1 for reference) and estimates on Emergency Items, Hazard Mitigation, and Emergency Planning (in Columns 2-4). Exposure to the earthquakes has a positive and statistically significant effect on households having emergency items, both in the short term and the long term. The short-term effect (in period 9) of exposure to earthquakes on having emergency items is 0.56 standard deviations or having 0.95 more emergency items out of eight. The effect decreases in the long term (in period 13) to 0.31 standard deviations, which is the equivalent to having 0.52 more emergency items. This decline is statistically significant (see p-value of the F-test for equality of these shortterm and long-term impacts in Table 2.3).

The short-term and long-term effects on taking hazard mitigation actions are positive. However, only the long-term effect is statistically significant. The short-term effect (in period 9) on hazard mitigation is 0.13 standard deviations or an increase of 0.21 out of two actions. This effect is comparatively small and not statistically significant. The absence of a significant effect reflects that securing furniture and hot water cylinders is more difficult and takes some time to organize. In the long term, this effect increases to 0.50 standard deviations and becomes statistically significant in period 10. It then decreases to 0.31 standard deviations but remains statistically significant in period 13 . 
Exposure to the earthquakes also positively affects having an emergency plan both in the short term and the long term. The short-term impact (in period 9) on having an emergency plan is 32 percentage points, which reduces to 15 percentage points in the long term (in period 13).

Where we find positive and statistically significant effects in all our specifications, Russell et al. (1995) only finds that exposure to an earthquake affects one out of six specifications. This difference in results might be due to differences in study designs. We focus on the impact of exposure to earthquakes on preparedness. In contrast, they jointly examine the impact of exposure to earthquakes and some of its consequences (e.g. fear during earthquake, earthquake damage) on preparedness. These consequences might have captured the impact of exposure to earthquake on preparedness in the specifications for which they do not find an impact. 
TABLE 2. 3: THE IMPACT OF EXPOSURE TO EARTHQUAKES ON DifFERENT Preparedness Measures

\begin{tabular}{|c|c|c|c|c|}
\hline \multirow{2}{*}{ Dependent Variables: } & (1) & (2) & (3) & \multirow{2}{*}{$\begin{array}{c}(4) \\
1 \text { if } \\
\text { Emergency } \\
\text { Planning }\end{array}$} \\
\hline & $\begin{array}{c}\text { Std. } \\
\text { Preparedness }\end{array}$ & $\begin{array}{l}\text { Std. } \\
\text { Emergency } \\
\text { Items }\end{array}$ & $\begin{array}{c}\text { Std. } \\
\text { Hazard } \\
\text { Mitigation }\end{array}$ & \\
\hline Earthquake Affected * Period 7 & $\begin{array}{l}0.32^{* * *} \\
(0.074)\end{array}$ & $\begin{array}{l}0.25^{\star * *} \\
(0.070)\end{array}$ & $\begin{array}{c}0.17^{*} \\
(0.089)\end{array}$ & $\begin{array}{l}0.19^{* * *} \\
(0.039)\end{array}$ \\
\hline Earthquake Affected * Period 8 & $\begin{array}{l}0.40^{\star * *} \\
(0.076)\end{array}$ & $\begin{array}{l}0.25^{\star \star \star} \\
(0.069)\end{array}$ & $\begin{array}{c}0.27^{* *} \\
(0.117)\end{array}$ & $\begin{array}{l}0.21^{* * *} \\
(0.056)\end{array}$ \\
\hline Earthquake Affected * Period 9 & $\begin{array}{l}0.67^{\star \star *} \\
(0.071)\end{array}$ & $\begin{array}{l}0.56^{\star * *} \\
(0.068)\end{array}$ & $\begin{array}{c}0.13 \\
(0.199)\end{array}$ & $\begin{array}{l}0.32^{\star * *} \\
(0.073)\end{array}$ \\
\hline Earthquake Affected * Period 10 & $\begin{array}{l}0.54^{* * *} \\
(0.066)\end{array}$ & $\begin{array}{l}0.38^{\star * *} \\
(0.073)\end{array}$ & $\begin{array}{l}0.50^{* * *} \\
(0.082)\end{array}$ & $\begin{array}{l}0.17^{* * *} \\
(0.034)\end{array}$ \\
\hline Earthquake Affected * Period 11 & $\begin{array}{l}0.54^{\star \star \star} \\
(0.070)\end{array}$ & $\begin{array}{l}0.41^{\star \star \star} \\
(0.063)\end{array}$ & $\begin{array}{l}0.45^{\star \star \star} \\
(0.093)\end{array}$ & $\begin{array}{l}0.15^{\star * *} \\
(0.038)\end{array}$ \\
\hline Earthquake Affected * Period 12 & $\begin{array}{l}0.54^{* * *} \\
(0.067)\end{array}$ & $\begin{array}{l}0.47^{\star \star \star} \\
(0.055)\end{array}$ & $\begin{array}{l}0.30^{\star \star *} \\
(0.078)\end{array}$ & $\begin{array}{l}0.18^{* * *} \\
(0.039)\end{array}$ \\
\hline Earthquake Affected * Period 13 & $\begin{array}{l}0.42^{\star \star \star} \\
(0.074)\end{array}$ & $\begin{array}{l}0.31^{* * *} \\
(0.075)\end{array}$ & $\begin{array}{l}0.31^{\star * *} \\
(0.087)\end{array}$ & $\begin{array}{l}0.15^{\star \star \star} \\
(0.043)\end{array}$ \\
\hline Observations & 20,148 & 20,148 & 15,747 & 20,148 \\
\hline R-squared & 0.098 & 0.101 & 0.027 & 0.041 \\
\hline Pre-earthquake Preparedness Average & 0 & 0 & 0 & 0.276 \\
\hline $\mathrm{p}$-values of F-test for equality of all interaction terms & 0.002 & 0.0006 & 0.0536 & 0.430 \\
\hline $\begin{array}{l}\text { p-values of F-test for equality of period } 8 \& 9 \text { 's } \\
\text { interaction terms }\end{array}$ & 0.005 & 0.0005 & 0.539 & 0.236 \\
\hline $\begin{array}{l}\text { p-values of F-test for equality of period } 9 \& 13 \text { 's } \\
\text { interaction terms }\end{array}$ & 0.007 & 0.0065 & 0.387 & 0.0439 \\
\hline
\end{tabular}

NOTE: All columns are estimated with OLS regressions. All specifications include a set of control variables controlling for demographic characteristics of the person from the household who completed the survey (ethnicity, age, age squared, sex, and whether they were born in New Zealand). Robust standard errors in parentheses are clustered at area level. ${ }^{* * *} p<0.01,{ }^{* *} p<0.05,{ }^{*} p<0.1$.

\subsubsection{Distinct Preparedness Activities Estimates}

To further examine what households do to prepare for earthquakes, we estimate the short-term and long-term effects on each of the 11 preparedness activities. Figure 2.7 shows the impacts on preparedness activities in period 9 and 13 (see Table A4 in the Appendix for estimates in all seven post-earthquake periods). Our findings reveal two patterns.

First, the results show stronger effects on the activities for which households were less prepared for before the earthquakes. We find the largest effects 
in the short term on water storage (28 percentage points) and emergency planning (32 percentage points). Before the earthquakes, households had a lot of room for improvement for these activities. Only $40 \%$ had enough water stored, and only $30 \%$ of households had an emergency plan before the earthquakes (see Table 2.1). In contrast, the effects on having a can opener (2 percentage points) and having a torch (2 percentage points) are negligible. This is likely because more than $90 \%$ of households already had a can opener and torch before the earthquakes.

Second, the effects decrease from the short term to the long term for items that need maintenance. The long-term effect decreases substantially when it comes to households having water and food, and storing spare batteries. For example, the effect on food storage is 8 percentage points in the short term, which reduces to 2 percentage points and becomes insignificant in the long term. This suggests that people forget to maintain their stored emergency food. These findings are in line with the findings of Mulilis et al. (1990), which suggest people need to be regularly reminded to stay prepared. 
FIGURE 2. 7: THE SHORT-TERM AND LONG-TERM EFFECTS OF INDIVIDUAL

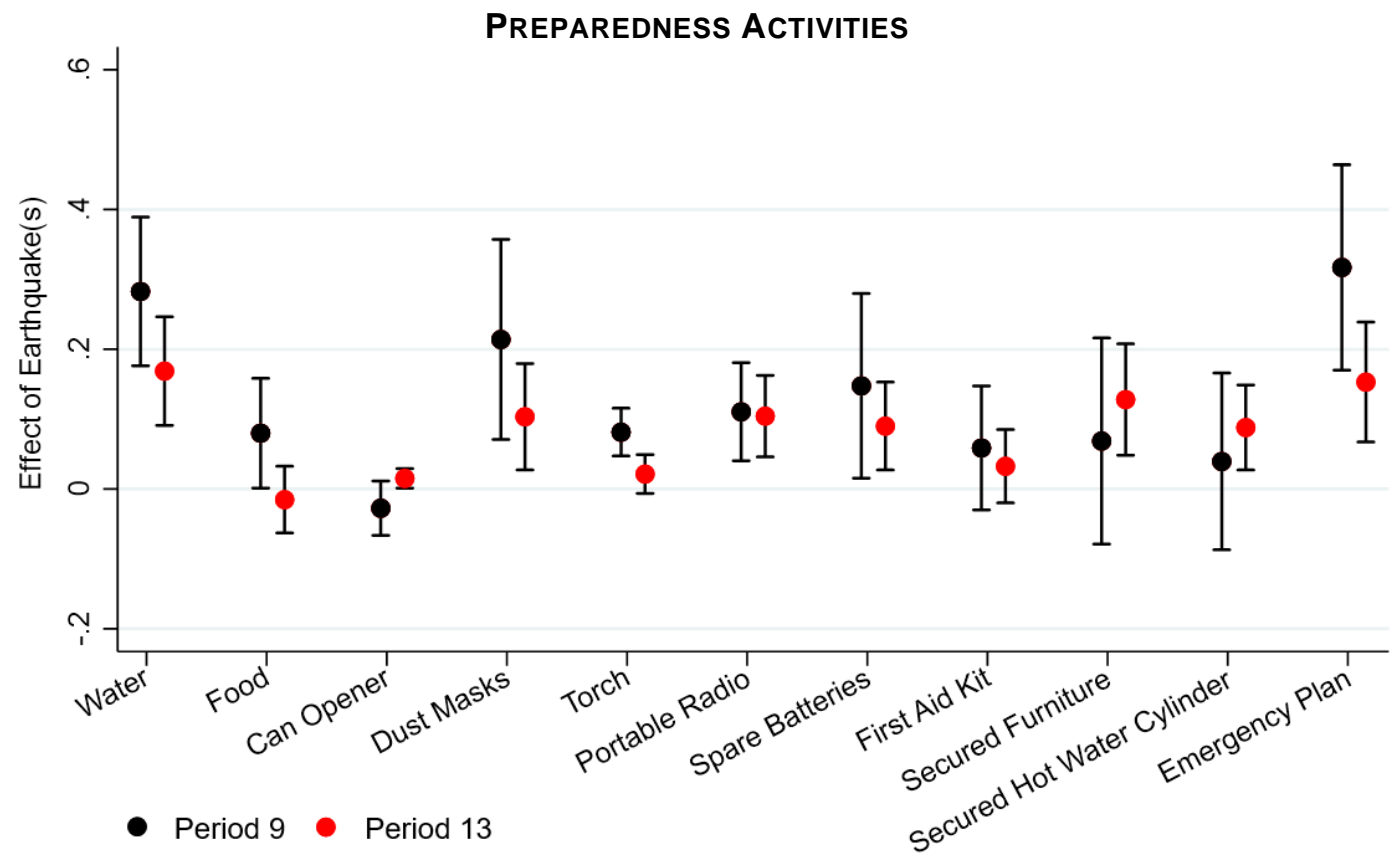

NOTE: The black dots (left) are the short-term effects of exposure to earthquakes on preparedness activities in period 9, and the red dots (right) are the long-term effects in period 13. See Table A4 in the appendix for the underlying regression estimates. The coefficients and their $95 \%$ Confidence Intervals are based on clustered standard errors at area level.

\subsection{Conclusion}

Our findings show that exposure to major earthquakes affects household preparedness positively and significantly in both the short term and the long term. The positive impact of exposure to earthquakes on household preparedness lasts for more than two years and starts to decline after that. However, even after two years, the impact remains positive.

Our estimates are likely an underestimation of the effect of the Canterbury earthquakes. These earthquakes were considered a tragedy and covered widely in the national news. Likely as a result of this general awareness, the "unaffected" areas also see a small improvement in earthquake preparedness (see Figure 5). With our difference-in-difference method, we 
identify the effects of experiencing the earthquakes personally on top of any general awareness effects.

These effects might be driven by different mechanisms in the short term and the long term. The short-term improvement in preparedness might be due to a reduction in optimism bias after experiencing earthquakes. Experiencing an earthquake may remind people that they are just as likely as their neighbours to be victims of a disaster (Burger \& Palmer, 1992). The reduction in optimism bias might also be driven by heightened risk communication through regular reminders to households from media and authorities about the risk of more aftershocks (Orchiston et al., 2013; McBride et al., 2019).

A number of mechanisms can explain why the effect of earthquakes reduced but remained positive in long term. Some of these long-term improvements might be the direct consequences of actions taken in short term. For example, households that buy a water container in the short term will also find it easier to store water in the long term. However, we may see reductions in preparedness over time since some households forget to replace their water. Households may also have permanently changed their beliefs about how likely earthquakes are. This is particularly likely for the earthquakes we study because the Canterbury region was not known to be at high risk of earthquakes before 2010. Relatedly, this awareness of greater earthquake risk might have led to a stronger focus on preparedness by local organizations such as schools.

Our study provides two lessons for policy makers. First, following an earthquake, people are more inclined to improve their preparedness in the short term. Policy makers can take advantage of this by running campaigns encouraging earthquake preparedness immediately after an earthquake. Such an attempt was made by New Zealand authorities in May 2011, three 
months after the second Canterbury earthquake, by holding a Preparedness Day to publicise and promote community preparedness. Such activities may be among the mechanisms responsible for the increase in preparedness in New Zealand after the earthquakes. Second, people become less prepared over time when it comes to items that require longterm maintenance. Therefore, policy makers may want to remind people to remain prepared by, for example, regularly refreshing their water supplies. 


\section{Appendix A}

TABle A 1: TABle of Modified Mercalli Index (MMI) Scale

Mercalli Equivalent Witness Observations

Intensity Richter

Magnitude

Felt by very few people; barely noticeable.

I $\quad 1.0$ to 2.0

II $\quad 2.0$ to 3.0

Felt by a few people, especially on upper floors.

III $\quad 3.0$ to 4.0

IV 4.0

V $\quad 4.0$ to 5.0

VI $\quad 5.0$ to 6.0

VII $\quad 6.0$

VIII $\quad 6.0$ to 7.0

IX $\quad 7.0$

$\times \quad 7.0$ to 8.0

Noticeable indoors, especially on upperfloors, but may not be recognized as an earthquake.

Felt by many indoors, few outdoors. May feel like heavy truck passing by.

Felt by almost everyone, some people awakened. Small objects moved. trees and poles may shake.

Felt by everyone. Difficult to stand. Some heavy furniture moved, some plaster falls. Chimneys may be slightly damaged.

Slight to moderate damage in well built, ordinary structures. Considerable damage to poorly built structures. Some walls may fall.

Little damage in specially built structures. Considerable damage to ordinary buildings, severe damage to poorly built structures. Some walls collapse.

Considerable damage to specially built structures, buildings shifted off foundations. Ground cracked noticeably. Wholesale destruction. Landslides.

Most masonry and frame structures and their foundations destroyed. Ground badly cracked. Landslides. Wholesale destruction.

XI $\quad 8.0$

Total damage. Few, if any, structures standing. Bridges destroyed. Wide cracks in ground. Waves seen on ground.

XII $\quad 8.0$ or greater

Total damage. Waves seen on ground. Objects thrown up into air.

SOURCE: Michigan Tech, UPSeis program. http://www.geo.mtu.edu/UPSeis/Mercalli.html 
TABle A 2: Comparison of Demographic Characteristics before AND AFTER the SAMPLE RESTRICTIONS

\begin{tabular}{lccccc} 
& \multicolumn{1}{c}{$\begin{array}{c}\text { N before } \\
\text { restrictions }\end{array}$} & $\begin{array}{c}\text { mean before } \\
\text { restrictions }\end{array}$ & $\begin{array}{c}\text { N after } \\
\text { restrictions }\end{array}$ & $\begin{array}{c}\text { mean after } \\
\text { restrictions }\end{array}$ & $\begin{array}{c}\text { mean } \\
\text { differences }\end{array}$ \\
\cline { 2 - 6 } European & 25,733 & 0.75 & 20,148 & 0.75 & 0.00 \\
Maori & 25,733 & 0.07 & 20,148 & 0.07 & 0.00 \\
Pacific & 25,733 & 0.03 & 20,148 & 0.03 & 0.00 \\
Asian & 25,733 & 0.06 & 20,148 & 0.06 & 0.00 \\
Other Ethnicities & 25,733 & 0.03 & 20,148 & 0.03 & 0.00 \\
Dual Ethnicity & 25,733 & 0.06 & 20,148 & 0.06 & 0.00 \\
Missing Ethnicities & 25,733 & 0.001 & 20,148 & 0.001 & 0.00 \\
Born in New Zealand & 25,733 & 0.77 & 20,148 & 0.77 & 0.00 \\
Female & 25,733 & 0.56 & 20,148 & 0.55 & 0.01 \\
Age & 25,733 & 48.87 & 20,148 & 48.97 & -0.10
\end{tabular}


Table A 3: Cronbach's Alpha of the Measure of Preparedness

\begin{tabular}{|c|c|c|c|c|c|c|}
\hline Item & Obs & Sign & $\begin{array}{c}\text { item-test } \\
\text { correlation }\end{array}$ & $\begin{array}{l}\text { item-rest } \\
\text { correlation }\end{array}$ & $\begin{array}{c}\text { average } \\
\text { interitem } \\
\text { correlation }\end{array}$ & alpha \\
\hline Water & 20333 & + & 0.5203 & 0.3572 & 0.1473 & 0.6334 \\
\hline Food & 20354 & + & 0.5232 & 0.3602 & 0.1470 & 0.6329 \\
\hline Can_Opener & 20365 & + & 0.3876 & 0.2061 & 0.1632 & 0.6611 \\
\hline Dust_Masks & 20315 & + & 0.4908 & 0.3228 & 0.1509 & 0.6398 \\
\hline Torch & 20356 & + & 0.5287 & 0.3665 & 0.1464 & 0.6316 \\
\hline Portable_R O & 20337 & + & 0.5198 & 0.3562 & 0.1473 & 0.6334 \\
\hline Spare_Batt s & 20307 & + & 0.5627 & 0.4075 & 0.1422 & 0.6238 \\
\hline Firstaid_Kit & 20345 & + & 0.5357 & 0.3751 & 0.1455 & 0.6300 \\
\hline Secured_Fe e & 17300 & + & 0.4068 & 0.2282 & 0.1595 & 0.6550 \\
\hline Secured_Ho r & 18647 & + & 0.3214 & 0.1356 & 0.1692 & 0.6707 \\
\hline Emergency_ n & 20344 & + & 0.4655 & 0.2934 & 0.1538 & 0.6451 \\
\hline Test scale & & & & & 0.1521 & 0.6636 \\
\hline
\end{tabular}


Table A 4: Estimates for EAch Preparedness Activity

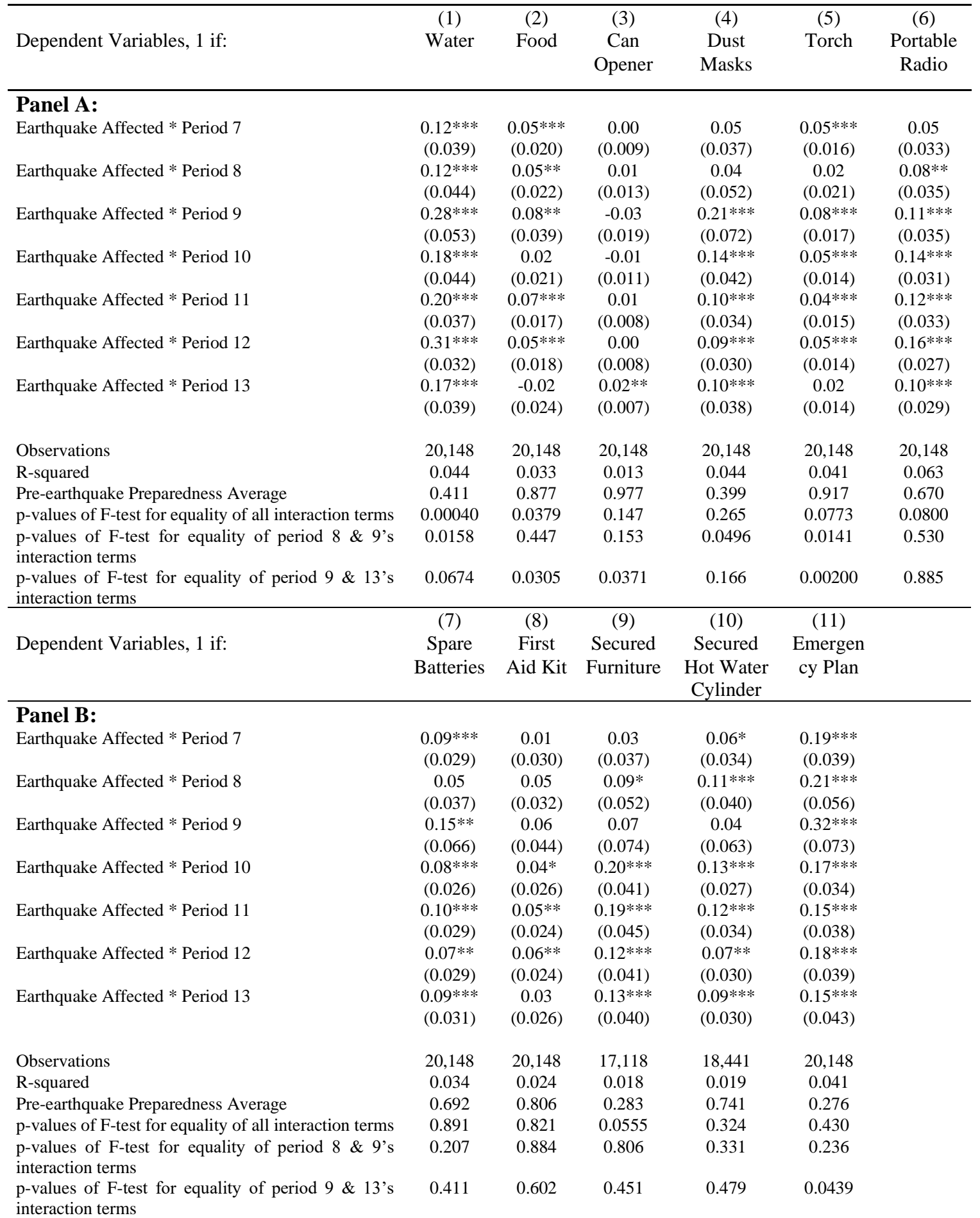

NOTE: All columns are estimated with OLS regressions. All specifications include a set of control variables controlling for demographic characteristics of the person from the household who completed the survey (ethnicity, age, age squared, sex, and whether they were born in New Zealand). Robust standard errors in parentheses are clustered at area level. ${ }^{* *} p<0.01,{ }^{* *} p<0.05,{ }^{*} p<0.1$. 


\section{CHAPTER 3: \\ Do People Pay More Attention to \\ Earthquakes in Western Countries?}

\subsection{Introduction}

Public attention to critical events is important because it leads to action from non-profit organizations and governments (Newig, 2004; Newell, 2006). For example, the rise in media attention to the issue of climate change during 2006-2007 led to a considerable increase in national climate legislations in 2007-2008 (Schmidt et al., 2013). Yet, we know little about what generates public attention.

There is anecdotal evidence that people from Western countries pay more attention to critical events in Western countries. Take, for example, natural disasters that hit a country unexpectedly. Franks (2006) points out that the reporting and perception of disasters in Western countries is uneven. She compares the media coverage of hurricane Katrina in the United States and hurricane Stanley in Guatemala that struck within weeks from each other in 2005. By the end of January 2006, the newspapers in the United Kingdom referred to hurricane Katerina 3,105 times, while there were only 34 mentions of hurricane Stanley. This comparison, however, only relies on two natural disasters. Furthermore, Frank looks at media coverage and not public attention directly. Media coverage might have other drivers such as media's ability to cover certain events. We do not know whether people are biased towards natural disasters in Western countries as well.

In this paper, we test whether people from Western countries pay more attention to earthquakes in Western countries holding constant earthquake characteristics such as, the magnitude of earthquake, number of death, and 
whether the earthquake generated tsunami. We measure public attention using the proportion of Google searches on the keyword "earthquake + country name" from internet users of the United States, the United Kingdom, Canada, Australia, and New Zealand to 610 significant earthquakes across the world from 2006-2016. We broadly follow Samuel Huntington (1993) and categorize Western countries as Western Europe, the United States, Canada, Australia, and New Zealand. ${ }^{4}$

Holding constant earthquake severity, we find that earthquakes in Western countries receive 44 percent more attention. This result stays statistically significant and increases to 57 percent after controlling for a number of geographical and social characteristics. Conversely, when we additionally control for economic development our result becomes insignificant and its magnitude drops to 2.5 percent. An in-depth examination on the attention paid to earthquakes in Western countries separately shows earthquakes in most Western countries receive significantly more attention than earthquakes in non-Western countries. Taken together, these results support the idea of a consistent Western bias, which is driven by people's biased attention towards events in developed countries.

A number of studies have investigated the determinants of media attention to natural disasters (Simon, 1997; Eisensee and Strömberg, 2007; Van Belle, 2000; Koopmans and Vliegenthart, 2010). Koopmans and Vliegenthart (2010) investigate the determinants of media attention from the

${ }^{4}$ Beside these countries, Huntington recognizes Papua New Guinea and French Guiana as Western countries. We have decided to exclude them because they are not generally considered as Western countries. 
United States, the United Kingdom and the Netherlands to almost 1,300 earthquakes from around the world for the period 1990-2005. They find that earthquakes in Western countries as well as countries with higher GDP per capita receive more media coverage in American, British and Dutch newspapers compared to non-Western countries and countries with lower GDP per capita. Van Belle (2000) also analyses the United States' media coverage of foreign disasters. He examines the impact of GDP per capita on the New York Times coverage of foreign disasters. Van Belle concludes that there is no evidence that GDP per capita is related to media coverage, a result that is clearly in contrast with the finding of Koopmans and Vliegenthart (2010). While these studies focus on media attention, we use Google Trends to measure public attention directly. Some factors including limited number of reporters in the country of earthquake or simultaneous media events like Olympics might have an influence on the media attention to earthquakes (Eisensee and Strömberg, 2007), while, nowadays the events that grab people's attention are not limited to those that are covered in media. In sum, we are the first to examine explicitly whether people as opposed to the media in Western countries pay more attention to earthquakes struck in Western countries.

\subsection{Data and Empirical Strategy}

\subsubsection{Data}

We obtain the data on earthquakes from the global significant earthquake database provided by National Oceanic and Atmospheric Administration (National Geophysical Data Center, 2017). This database contains information on earthquakes that meet at least one of the following criteria; 10 or more deaths, approximately $\$ 1$ million or more damage, a magnitude of 7.5 on the Richter scale or greater, the Modified Mercalli 
Intensity (MMI) of $\mathrm{X}$ or greater $^{5}$, or whether the earthquake generated a tsunami. In our analysis, we control for earthquake characteristics including magnitude, death toll, and whether the earthquake generated tsunami. Table 3.1 shows summary statistics for our estimation sample.

Table 3. 1: Descriptive Statistics

\begin{tabular}{lccccc}
\hline & $(1)$ & $(2)$ & $(3)$ & $(4)$ & $(5)$ \\
& $N$ & Mean & Sd & Min & Max \\
\hline & & & & & \\
Public Attention & 2,950 & 1.42 & 8.38 & 0 & 100 \\
Western & 2,950 & 0.15 & 0.36 & 0 & 1 \\
Magnitude & 2,950 & 5.98 & 1.09 & 1.60 & 9.10 \\
Tsunami & 2,950 & 0.20 & 0.40 & 0 & 1 \\
Number of Deaths & 2,950 & 728.3 & 13,490 & 0 & 316,000 \\
Distance (in 10,000 kms) & 2,950 & 0.994 & 0.424 & 0.019 & 1.959 \\
Common Border & 2,950 & 0.02 & 0.12 & 0 & 1 \\
Share of Migrants & 2,950 & 0.25 & 0.44 & 0 & 5.75 \\
Colony & 2,950 & 0.07 & 0.25 & 0 & 1 \\
Share of Christians & 2,950 & 0.43 & 0.41 & 0.00 & 0.99 \\
Common Official First Language & 2,950 & 0.29 & 0.45 & 0 & 1 \\
GDP per capita (in \$10,000s) & 2,950 & 1.224 & 1.572 & 0 & 6.221 \\
& & & & & \\
\hline
\end{tabular}

NOTE. - 'Sd' refers to the standard deviation of the respective variable.

We use Google Trends - an online tool for exploring people's search behaviour - to collect Google search data from our 6 countries of attention. Google Trends is an analytical tool that provides data on the proportion of Google searches on a particular topic, reflecting Google Users' interest in that topic. This analytical tool allows for comparison between different topics adjusting for time and location. It takes a random sample of Google search

\footnotetext{
${ }^{5}$ Intensity refers to the effect of an earthquake on the Earth's surface. Intensity $X$ represents extreme shaking which is the severest among MMI degrees of shaking (Wood and Neumann, 1931). An earthquake with MMI $X$ destroys some well-built wooden structures (most masonry and frame structures destroyed with foundations. Rails bent)
} 
data as representative of all Google searches and provides a proportionate measure scaled from 0-100 that shows the amount of Google searches on a particular topic in a given time and location. This scaling means that Google Trends data adjusts for differences in number of internet users in different locations (Google, 2017). We collect the data for Google search from the United States, the United Kingdom, Canada, Australia, and New Zealand on the search term "earthquake + country name" in the month in which the earthquake occurred.

We measure attention exploring Google Trends data for "earthquake + country name" and adjusting the search for geolocation and time period on interest. We obtain the monthly Google Trends score of our keywords from 2006 until 2016 and limiting the origin of search to the United States, the United Kingdom, Canada, Australia, and New Zealand, one at a time. Since Google Trends allows for comparison between different keywords, we use the keywords for all the earthquakes to identify the earthquake that received the highest amount of attention in the sample period in a given country. For example, Google users in the United States paid the highest attention to "Earthquake Japan" on March of 2011, and for this reason, its Google Trends score is 100 . This earthquake, also known as Japan's Great Sendai earthquake, had a magnitude of 9 on the Richter scale generated a tsunami, which caused nuclear accidents in Japan. Compared to the Great Sendai earthquake, "Earthquake Haiti" - the earthquake that hit in 2010 and killed more than 300,000 people - received a Google Trends score of 64 . This score means that number of the searches for Haiti earthquake is 64 percent of the number of searches of the Sendai earthquake. This procedure is shown in Figure 3.1. Unfortunately, Google Trends does not provide information on the absolute number of searches. 
Figure 3. 1: IlLUStration of DATA EXtraction from GoOgLe TRENDS

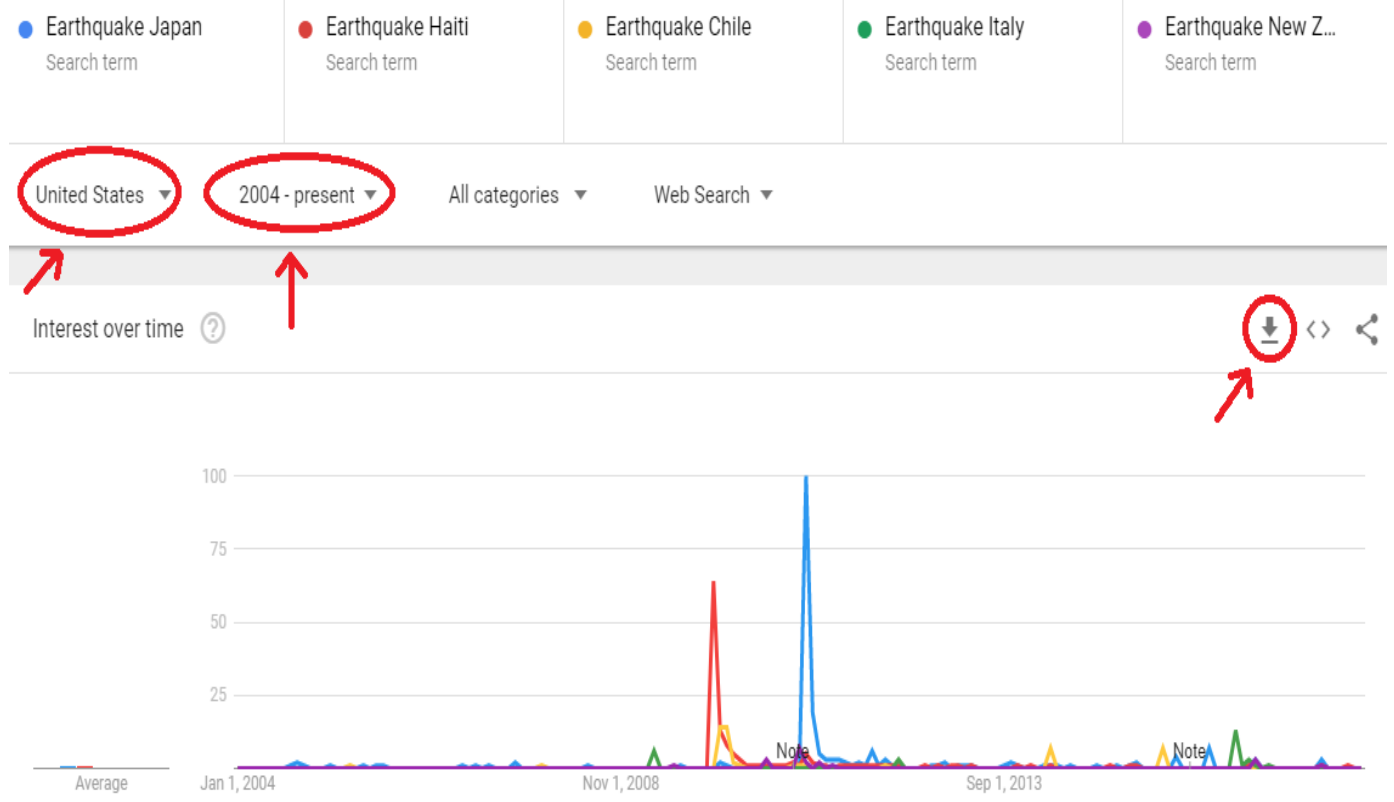

Following this approach, we obtain the data on the proportion of Google searches on our 610 earthquakes of interest from the mentioned five countries for the period of 2006-2016. As shown in Table 3.1, the mean of public attention equals 1.42 percent, which is 1.42 percent of the earthquake that received the highest attention in a given country. Figure 3.2 shows the distribution of public attention and log of public attention. The skewed distribution and considerably low mean are the result of the fact that people pay so much attention to few earthquakes while so many earthquakes barely receive any attention. 
Figure 3. 2: Distribution of Public Attention
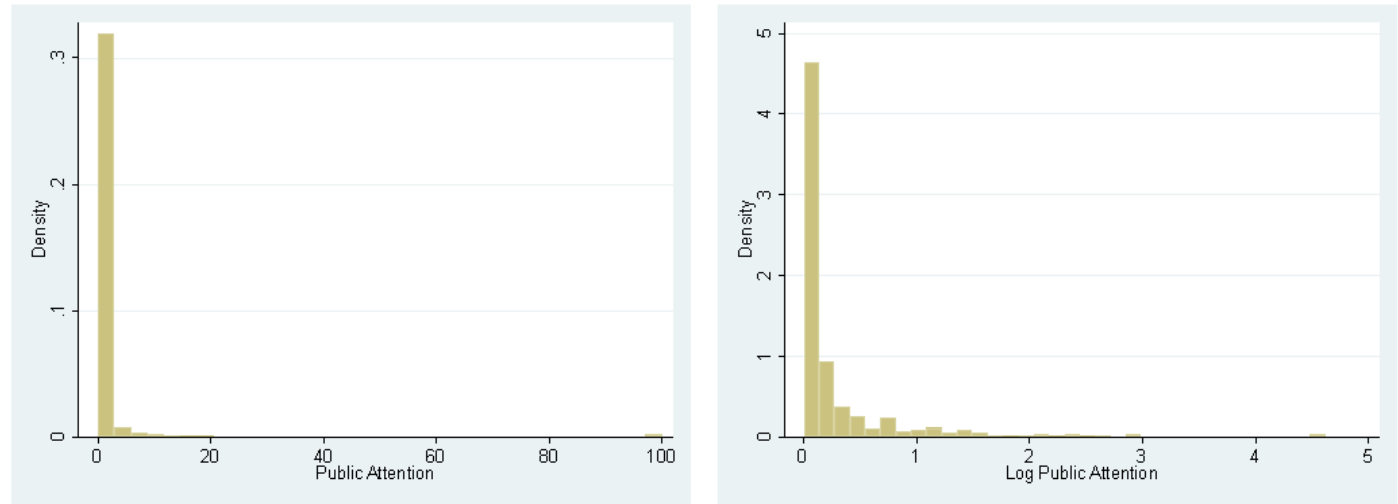

To understand our measure of public attention better, we assess the correlation between our Google Trends scores and the news coverage of the same search terms in 5 news agencies in the US namely CNN, Fox News, New York Times, and Huffington Post. This is to check whether and to what extend the volume of Google searches related to earthquakes are correlated with the media coverage of earthquakes in the US. To get the data on news coverage we search the websites of these news agencies for "earthquake + country name". To avoid counting the same coverage multiple times, we limit the search to the term appearing in the title of the page only. We find that Google Trends score for our earthquakes keywords is highly but imperfectly correlated with the news coverage of the same keywords. All of the correlation are between 0.704 (for Huffington Post) and 0.798 (for CNN). This result shows that media attention is not the same as public attention. There are instances that people want to know about an occurrence that is not covered in media, so they search directly. Nowadays people often use search engines to find more information about a topic and Google is by far the most popular search engine in the world as well as the five countries that we measure their public attention. Google captured almost $87 \%, 90 \%, 94 \%, 95 \%$, and $91 \%$ of the market share of search engine users in the United States, the United Kingdom, Australia, New Zealand, and Canada respectively in 2017 . This share on average is almost 
17 times higher than the share of second popular search engine (Bing) in these countries (Stats, 2017).

Our explanatory variable of interest is a Western dummy. Relying broadly on Huntington (1993), we categorize Western countries as countries in Western Europe, the United States, Canada, Australia, and New Zealand. Almost $15 \%$ of earthquakes in our database struck in Western countries.

We categorize our control variables into three categories, geographical, social, and economic characteristics. Geographical characteristics includes the distance in kilometres and neighbour. The data on these two variables is available on GeoDist database (CEPII, 2017). This database uses longitudes and latitudes of the most important cities of countries and measures the distance between the country of attention and the country in which the earthquake struck. Neighbour indicates whether the two countries are contiguous. We expect people pay less attention to the events in the countries that are far from them and pay more attention to the events in their neighbouring countries. Social characteristics include common official first language, colony, share of migrants, and share of Christians. The data on common official first language and colony is also available on GeoDist database (CEPII, 2017). We use the data on bilateral migration from the World Bank (Özden et al., 2011) to measure the share of migrants from the country of earthquake in the country of where we measure attention. Finally, we obtain the data on the share of Christians in the countries of earthquake in 2015 from World Christian Database (Johnson and Zurlo, 2007). We expect people pay more attention to the events in the countries with them have social ties. Lastly, we use GDP per capita in USD as our measure of Economic characteristics and obtain the data on countries GDP per capita from the World Bank. 


\subsubsection{Empirical Strategy}

In order to understand the role of Western country status in the public attention paid to earthquakes, we estimate four specifications using the following empirical model:

$$
\left.\operatorname{Ln}_{\left(\text {Attention }_{i c}\right.}\right)=\beta_{1} \text { Western }_{i}+\delta X_{i c}^{\prime}+u_{i c}
$$

where $L n\left(\right.$ Attention $\left._{i c}\right)$ is the natural logarithm of Google Trends score for earthquake $i$ in country $c$ (country of attention) which is our measure of public attention. Because we have many values between zero and one, we add one to the Google Trends score and take its log. Western ${ }_{i}$ is a dummy variable that is equal to one if the earthquake struck in a Western country. The coefficient of interest is $\beta_{1}$ which shows the increase in public attention when the earthquake occurred in a Western country. To allow for number of death and magnitude to have non-linear effects on attention, we include cubic polynomials of magnitude and number of deaths. In all specifications, we control for Earthquake characteristics including magnitude, the number of death and a tsunami dummy. We also include country of attention fixed effects. To account for countries paying more attention to earthquakes in their own country we include a domestic dummy. Because we observe the attention to the same earthquake from five countries, our independent variable of interest varies at the country level. Therefore, we cluster standard errors at the country of earthquake level.

The vector $X_{i c}^{\prime}$ contains our three sets of control variables, geographical, social, and economic characteristics that we include in some of our specifications. Geographical characteristics contains bilateral distance and neighbour that is a dummy variable equalling one when the two countries are contiguous. We control for these two variables since people might pay more attention to a close or a neighbouring country that is a Western country as well. Social characteristics contains four control variables. Share of 
migrants, which is the share of migrants from country of earthquake in country of attention, and share of Christians in country of earthquake, a dummy for whether the country of earthquake and country of attention had colonial ties, and a dummy if the two countries share an official first language. We control for these variables since people might pay more attention to earthquakes in countries with them, they have some social similarities. Our measure of economic characteristics is GDP per capita of the country of earthquake. We include this variable in the last specification to find whether the wealth of Western countries contributes to the hypothetical Western bias.

\subsection{Results}

Table 3.2 shows how Western country status predicts public attention in the United States, the United Kingdom, Canada, Australia, and New Zealand. We find that people in these countries pay more attention to earthquakes in Western countries. Our results suggest that earthquakes in Western countries receive 0.37 log points - about 44 percent - more public attention compared to earthquakes in non-Western countries. This result stays consistent after controlling for geographical and social characteristics (columns 1, 2, and 3). However, after controlling for economic characteristics we get insignificant results for Western country status (column 4). Our results of this specification suggest that a $\$ 10,000$ increase in GDP per capita increases the public attention to earthquakes by 16 percent. The Western bias seems to be driven by people paying more attention to earthquakes in economically developed countries. The results of our last specification are consistent with Koopmans and Vliegenthart (2010) that gets insignificant results for Western country status when controlling for GDP per capita. 
Table 3. 2: Determinants of Public Attention to EARthquakes

\begin{tabular}{|c|c|c|c|c|}
\hline & (1) & (2) & (3) & (4) \\
\hline Dependent Variable: & $\begin{array}{l}\text { Log Public } \\
\text { Attention }\end{array}$ & $\begin{array}{l}\text { Log Public } \\
\text { Attention }\end{array}$ & $\begin{array}{l}\text { Log Public } \\
\text { Attention }\end{array}$ & $\begin{array}{l}\text { Log Public } \\
\text { Attention }\end{array}$ \\
\hline \multirow[t]{2}{*}{ Western } & $0.365^{\star \star *}$ & $0.376^{\star * *}$ & $0.454^{* * *}$ & 0.024 \\
\hline & $(0.095)$ & $(0.097)$ & $(0.084)$ & $(0.109)$ \\
\hline Distance (in 10,000 kms) & & $\begin{array}{l}-0.140^{* *} \\
(0.065)\end{array}$ & $\begin{array}{l}-0.127^{* *} \\
(0.062)\end{array}$ & $\begin{array}{l}-0.125^{* *} \\
(0.059)\end{array}$ \\
\hline Common Border & & $\begin{array}{l}-0.055 \\
(0.181)\end{array}$ & $\begin{array}{l}-0.166 \\
(0.124)\end{array}$ & $\begin{array}{l}-0.350^{* *} \\
(0.146)\end{array}$ \\
\hline Colony & & & $\begin{array}{l}-0.075 \\
(0.112)\end{array}$ & $\begin{array}{l}-0.092 \\
(0.117)\end{array}$ \\
\hline Common Official First Language & & & $\begin{array}{c}-0.136^{\star * \star} \\
(0.038)\end{array}$ & $\begin{array}{l}-0.089^{* *} \\
(0.041)\end{array}$ \\
\hline $\begin{array}{l}\text { Share of Migrants from country of } \\
\text { earthquake }\end{array}$ & & & $\begin{array}{c}0.167^{\star * *} \\
(0.048)\end{array}$ & $\begin{array}{l}0.160^{\star * \star} \\
(0.050)\end{array}$ \\
\hline Share of Christians & & & $\begin{array}{c}-0.189^{* * *} \\
(0.071)\end{array}$ & $\begin{array}{c}-0.187^{* * *} \\
(0.043)\end{array}$ \\
\hline GDP per capita (in $\$ 10,000$ s) & & & & $\begin{array}{l}0.146^{\star * *} \\
(0.027)\end{array}$ \\
\hline Earthquake Characteristics & YES & YES & YES & YES \\
\hline R-squared & 0.277 & 0.284 & 0.309 & 0.381 \\
\hline Observations & 2,950 & 2,950 & 2,950 & 2,950 \\
\hline
\end{tabular}

NOTE. - The dependent variables in all Columns are the log of public attention, which is a proportionate measure scaled from $0-100$ calculated by Google Trends. All columns are estimated with OLS regressions that include country-of-attention fixed effect, magnitude of the earthquakes, number of deaths and a dummy variable, which is equal to 1 if the earthquake generated tsunami. We include cubic polynomials of magnitude and number of deaths to control for their non-linear effects. The regressions also include a dummy variable, which is equal to 1 if the earthquake is stricken in the same country that attention is captured from. Robust standard errors in parentheses are clustered at country of attention and country of earthquake levels. ${ }^{*} p<0.1,{ }^{* *} p<0.05,{ }^{* * *} p<0.01$.

To find out whether our results generalises to all Western countries, we look at each Western countries separately. In particular, we estimate a model similar to the one in column 3 of Table 3.2 where we replace the Western dummy with separate dummy variables for each Western country. The coefficients of these dummies then show the estimated effect of each country on public attention where all non-Western countries are the base 
group. Figure 3.3 plots coefficient estimates of all Western country dummies separately. These dummies show that seven countries receive significantly more attention, while remaining country dummies are not significantly different from zero (see also Appendix B, table B1 for the underlying regression). Therefore, we find enough evidence to generalize our findings to all Western countries.

Figure 3. 3: Coefficient Plot of Western Country Dummies

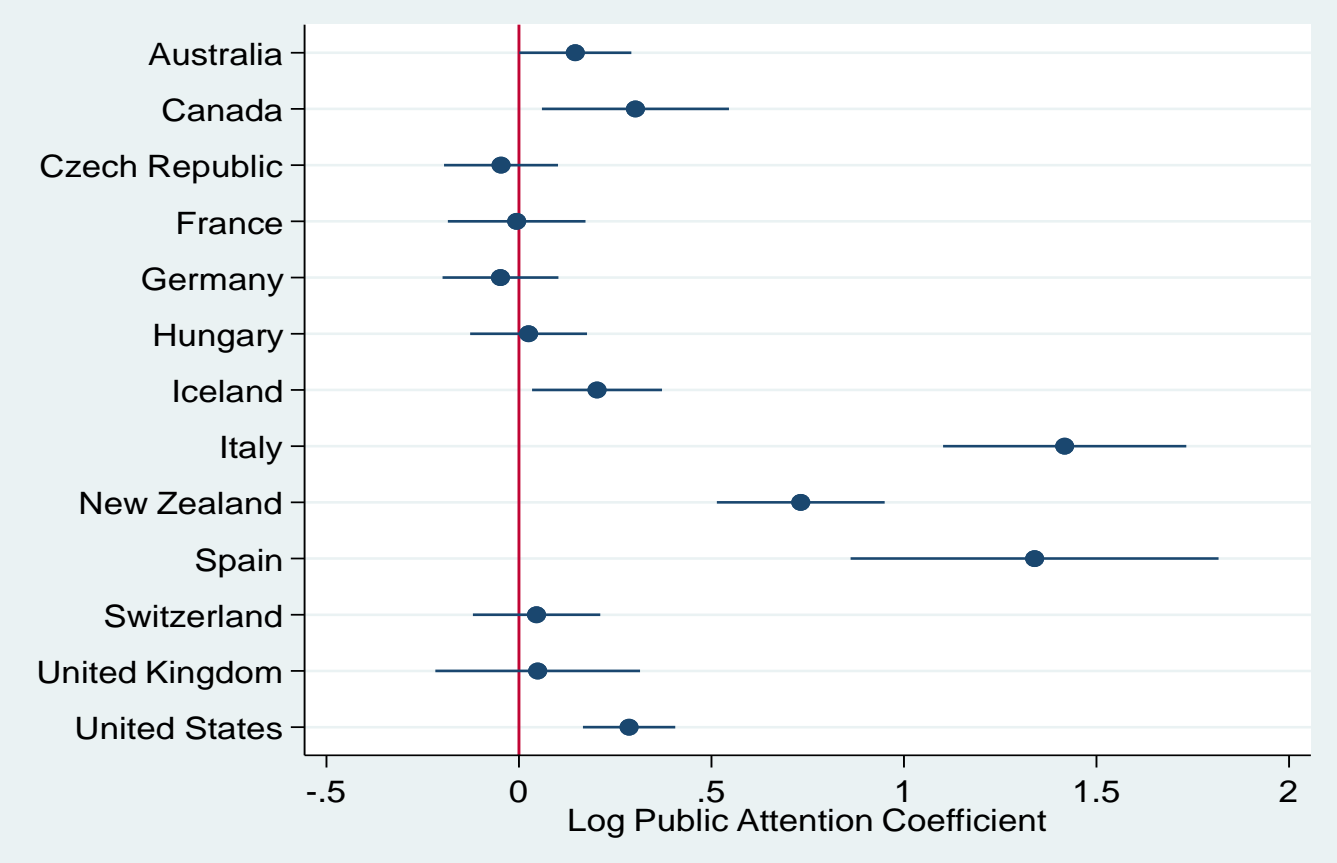

NOTE. - The dots are coefficients from estimates of table B1 countries influence on public attention, with non-Western countries as the base country in the appendix.

\subsection{Conclusion}

We estimate the role of Western countries status on the public attention paid to 610 earthquakes across the world from 2006 to 2016 from the United States, the United Kingdom, Canada, Australia, and New Zealand. Our findings show that people from these countries pay on average 50 percent more attention to earthquakes in Western countries. This result disappears after controlling for GDP per capita of the country in which earthquake is hit, 
suggesting that the bias in attention is mainly towards more financially developed countries rather than Western countries. A bias towards paying attention to earthquakes in developed countries might make it difficult to motivate governments to provide relief for less developed countries who need this help more urgently. 


\section{Appendix B}

TABLE B 1: WESTERN COUNTRIES SEPARATE COEFFICIENTS

\begin{tabular}{|c|c|}
\hline Dependent Variable: & Log Public Attention \\
\hline Distance (in 10,000 kms) & $\begin{array}{c}-0.142^{* * *} \\
(0.050)\end{array}$ \\
\hline Common Border & $\begin{array}{c}0.003 \\
(0.079)\end{array}$ \\
\hline Colony & $\begin{array}{c}-0.023 \\
(0.096)\end{array}$ \\
\hline Common Official First Language & $\begin{array}{c}-0.129^{* * *} \\
(0.034)\end{array}$ \\
\hline Share of Migrants & $\begin{array}{c}0.115^{\star \star *} \\
(0.034)\end{array}$ \\
\hline Share of Christians & $\begin{array}{c}-0.239^{* * *} \\
(0.073)\end{array}$ \\
\hline Australia & $\begin{array}{l}0.146^{* *} \\
(0.074)\end{array}$ \\
\hline Canada & $\begin{array}{l}0.303^{\star *} \\
(0.124)\end{array}$ \\
\hline Czech Republic & $\begin{array}{l}-0.047 \\
(0.075)\end{array}$ \\
\hline France & $\begin{array}{l}-0.006 \\
(0.091)\end{array}$ \\
\hline Germany & $\begin{array}{l}-0.048 \\
(0.077)\end{array}$ \\
\hline Hungary & $\begin{array}{l}0.0251 \\
(0.077)\end{array}$ \\
\hline Iceland & $\begin{array}{l}0.203^{* *} \\
(0.086)\end{array}$ \\
\hline Italy & $\begin{array}{l}1.417^{\star * *} \\
(0.161)\end{array}$ \\
\hline New Zealand & $\begin{array}{c}0.732^{* * *} \\
(0.111)\end{array}$ \\
\hline Spain & $\begin{array}{l}1.339^{* * *} \\
(0.243)\end{array}$ \\
\hline Switzerland & $\begin{array}{c}0.046 \\
(0.084)\end{array}$ \\
\hline United Kingdom & $\begin{array}{c}0.049 \\
(0.135)\end{array}$ \\
\hline United States & $\begin{array}{c}0.286^{* * *} \\
(0.061)\end{array}$ \\
\hline $\begin{array}{l}\text { Earthquake Characteristics } \\
\text { R-squared } \\
\text { Observations }\end{array}$ & $\begin{array}{l}\text { YES } \\
0.378 \\
2,950\end{array}$ \\
\hline
\end{tabular}

NOTE. - The countries are representative of Western countries' influence on public attention separately, with the non-Western countries as the base group. The dependent variables in all Columns are the log of public attention, which is scaled from 0-100 calculated by Google Trends. All columns are estimated with OLS regressions that include country-of-attention fixed effect, magnitude of the earthquakes, number of deaths and a dummy variable, which is equal to 1 if the earthquake generated tsunami. The regressions also include a dummy variable, which is equal to 1 if the earthquake is stricken in the country of attention. Robust standard errors in parentheses are clustered at country of attention and country of earthquake levels. ${ }^{\star} p<0.1,{ }^{\star \star} p<0.05,{ }^{* \star *} p<0.01$. 


\section{CHAPTER 4: \\ Predictors of International Public Attention to Disasters: Evidence from 18 Countries}

\subsection{Introduction}

After a disaster, many countries rely on receiving international support from foreign governments and international organizations. Such international support is in part driven by public attention (Newig, 2004; Becerra et al., 2014). It is therefore important to understand what predicts the public attention to disasters.

Three studies have identified predictors of public attention to disasters at an international level (Habibi \& Feld, 2018; Cavanagh et al., 2014; Choi et al., 2020). Habibi and Feld (2018) use Google search data to measure public attention and find a positive correlation between earthquakes in Western countries and the volume of Google search they receive from other Western countries. However, this association disappears after controlling for countries GDP per capita, suggesting that this apparent Western Bias is driven by Western countries' stronger economic power. Cavanagh et al., (2014) and Choi et al., (2020) also use Google search volume to investigate people's interest in the issue of climate change. Cavanagh et al., (2014) find that socioeconomic factors are the strongest predictors of public attention to climate change in the US. Choi et al., (2020) find that people who live in countries with abnormally higher local temperature search more about topics related to climate change. Apart from these attempts there is no comprehensive analysis on the predictors of public attention to disasters. Hence, the role of a number of important factors such as countries' political 
status and cultural similarities have not been investigated yet. Moreover, previous studies focus on predictors of public attention from Western countries only, and we do not know if these findings genialize.

In this paper, we investigate which factors predict how much public attention disasters receive at international level. We measure public attention using the volume of Google searches from internet users in 18 countries. These countries include six Western countries (the United States, the United Kingdom, Canada, Australia, New Zealand), four Latin American countries (Colombia, Argentina, Peru, Paraguay), four Arab countries (Lebanon, Jordan, Tunisia, Morocco), and four Sub-Saharan African countries (Ghana, Nigeria, Botswana, South Africa). We measure the attention paid to 372 earthquakes in 76 countries from 2004-2018. To keep track of whether we refer to a country in which we measured the attention or a county in which an earthquake hit, we use the terms countries of attention and countries of earthquake throughout the paper. The earthquakes we focus on are registered as disasters in The Emergency Events Database (EM-DAT). We look into the countries' social and cultural, economic, and political factors and connections separately. Throughout our analysis, we control for earthquakes' magnitude, number of people killed and affected, and the direct financial damages. We also control for geographical proximities such as distance in kilometre and shared borders. This approach allows us to compare earthquakes that are similarly destructive and similarly close to the country of attention to isolate the predictive power of the other factors of interest.

Our findings suggest that countries' social and cultural, economic, and political factors predict the public attention they receive from other countries. Earthquakes receive more attention form people in countries with a similar religion and culture. They also receive more attention if they have a higher 
GDP per capita, a higher volume of bilateral trade and when they are more democratic. Additionally, an in-depth examination of what predicts public attention in our four groups of countries shows that economic and political status of countries predict receiving more public attention from all four groups and therefore are universal. Social and cultural similarities, however, predict more public attention from Western and Latin American countries and less public attention from Arab and Sub-Saharan African countries. Since social and cultural similarities predict public attention in different directions for different samples, they cannot be considered as universal predictors of public attention.

Besides the literature on the predictors of public attention to disasters, there is a literature on the predictors of news attention to disasters as well (Simon, 1997; Van Belle, 2000; Koopmans \& Vliegenthart, 2010; Berglez \& Lidskog 2019). These studies also measure news attention to worldwide disasters from Western countries only. In the most comprehensive of these studies, Koopmans and Vliegenthart (2010) investigate the predictors of news attention most comprehensively by focusing on news attention from the United States, the United Kingdom, and the Netherlands to 1,300 earthquakes around the world during 1990-2005. They find press in these countries pay more attention to earthquakes in other Western countries, their touristic destinations, their trade partners, countries with higher GDP per capita, countries they have more immigrants from, and countries that are geographically closer.

While the interplay of news attention and public attention is undeniable, they differ from one another. News coverage of an event might be limited by factors such as the number of reporters in the country of event, the simultaneity of other news-worthy events such as Olympics (Eisensee and Strömberg, 2007), or the news agencies' agenda setting and preferences. 
Public attention, on the other hand, is the direct reflection of people's interest in the event. Public attention to an international event might therefore have different drivers than the news coverage of the event. Kwak et al., (2018) investigate the correlation between international news attention and international public attention in 193 countries. They use 14 months of longitudinal data of online news from Unfiltered News - a web service that indexes news articles in the database of Google News - to measure news attention, and they measure public attention with the volume of Google search from Google Trends. Their results show that often a country's news pays more attention to countries different from those its people are interested in. They find countries like the US, China, Syria, Egypt, and the UK to be frequently covered in the news, but fail to attract a similar amount of attention from people. However, the correlation between news and public attention varies depending on topics.

Our paper makes three contributions to the literature. First, we examine 11 predictors of public attention to disasters and uncover a broader range of predictors than the earlier studies. This broader range of predictors allows for a more thorough understanding of what country factors attract people's attention across the borders. Second, we examine a sample of 18 countries with a variety of social and cultural, economic, and political backgrounds. Examining such a sample allows for testing whether the predictors of public attention are universal or vary for different groups of countries.

Finally, our study compliments the literature on predictors of international news attention. Our findings on the predictors we examine in this paper are in line with the findings from the literature of news attention. Previous studies in the literature on news attention have found a positive correlation between international news coverage of a country and its economic power (Kim \& Barnett, 1996; Wu, 2000; Wu, 2007; Koopmans and Vliegenthart, 
2010; Segev, 2015; Grasland, 2020), trade relations (Wu, 2000; Koopmans and Vliegenthart, 2010; Segev, 2015), political freedom (Nnaemeka \& Richstad, 1981; Chang et al., 1987; Kim \& Barnett, 1996; Van Belle, 2000; Koopmans and Vliegenthart, 2010), and social proximity such as common language, common borders, and colonial ties (Chang et al., 1987; Kariel \& Rosenvall, 1984; Koopmans and Vliegenthart, 2010; Berglez \& Lidskog, 2019; Grasland, 2020). This indicates that in the context of disasters, the predictors of public attention are similar to the predictors of news attention.

\subsection{Data}

\subsubsection{Disasters}

We use the data on earthquakes from the EM-DAT database collected by the Centre for Research on the Epidemiology of Disasters. This database has worldwide coverage and registers earthquakes as a disaster if they meet at least one of the following criteria; 10 or more death, 100 or more affected people, a state of emergency declaration, or a call for international assistance. For the period 2004-2018, 372 earthquakes around the world are registered as disasters in EM-DAT database.

We measure the public attention to these earthquakes from 18 countries $^{6}$ around the world. Figure 4.1 highlights these countries in the world's map and shows how they are scattered in 5 continents. We select these countries considering two objectives; first, having enough variation with regards to countries' social and cultural, economic, and political

\footnotetext{
${ }^{6}$ We "only" include 18 countries because the data collection is time-consuming.
} 
backgrounds, and second, being able to break them into distinguishable groups for further analysis.

Figure 4. 1: The MAP of Countries of AtTEntion

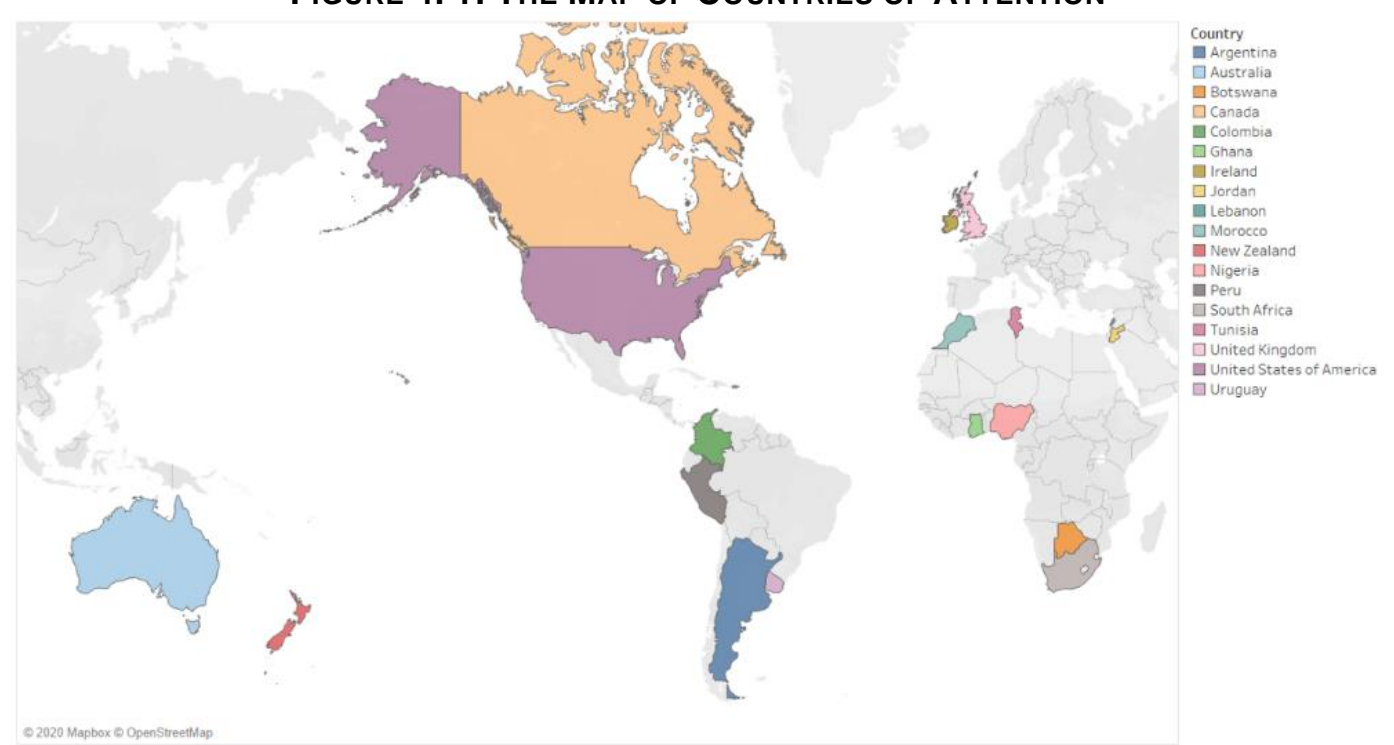

NOTE. - This map is made by Tableau based on Longitude and Latitude. We use different colours for countries to avoid confusion around the neighbouring countries.

Our sample of countries of attention offers a large variety of social and cultural, economic, and political backgrounds. It can be broken into four groups - Western, Latin American, Arab, and Sub-Saharan African countries - where the countries in each group have the same language, dominant religion, and share other cultural similarities. The sample includes 6 developed and 12 developing economies, with their GDP per capita varying within the wide range of $\$ 2,028$ - $\$ 78,806$ in 2018 . It also provides a good variation of political regimes with an average of $52 \%$ liberal democracy, $28 \%$ electoral democracy, $9 \%$ electoral autocracy, and $\% 11$ closed autocracy. 


\subsubsection{Public Attention}

We measure public attention using monthly Google Trends data. Google Trends is an analytical tool that provides data on the volume of Google searches on a particular topic, reflecting Google users' interest in that topic. People often use search engines to find more information about a topic and Google is by far the most popular search engine in the 18 countries included in our study. On average, Google captures $94 \%$ of market share of the countries in our sample (Stats, 2020).

Google Trends takes a random sample of Google search data as a representative of all Google searches and provides a proportionate measure scaled from 0-100. This scaling means that Google Trends data adjusts for differences in number of internet users in different locations (Google, 2017). Yet, since the share of internet users in our countries of attention varies from $26 \%$ to $95 \%$ (see Figure 4.2 ). Our findings in countries with lower share of internet users may therefore mainly reflect the attention from those having internet access rather than the whole population. 
Figure 4. 2: Percent of Internet Users in Countries of Attention

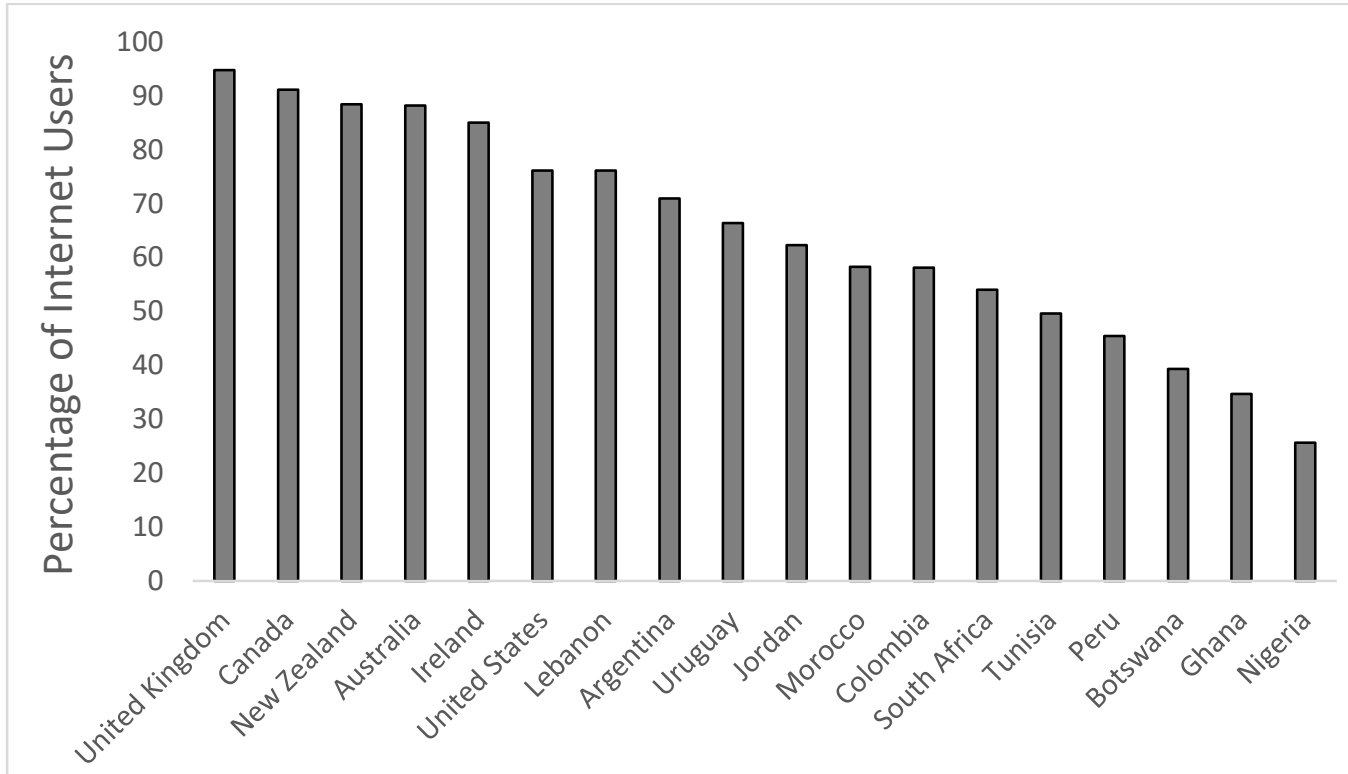

Country of Attention

NOTE. - We obtained the data on share of internet users in 2016 from Our World in Data: available at https://ourworldindata.org/

We use Google Trends - an online tool for exploring people's search behavior - to collect Google search data from our 18 countries of attention on the search term 7 "earthquake + country name" in the official language of

${ }^{7}$ Using Google Trends, we can define the search words as "search terms" or "search topics". Search terms show matches for all terms in the query, in the language given, where search topics are suggested by Google Trends and include a group of terms that share the same concept in any language. While using "search topics" can minimize neglecting relevant searches to an earthquake, Google Trends provides a "search topic" only for well-known earthquakes. Since there is no "search topic" associated with more than two third of the earthquakes in our database, we use "search terms" to capture the volume of Google searches on all earthquakes provided by EM-DAT. 
each country. ${ }^{8}$ Google Trends allows for adjusting the time and location of queries. These options allow us to limit the duration of search to 2004-2018 and limit the origin of search to the countries of attention, one at a time. Google Trends also allows for comparison between five different keywords at a time. This option allows us to compare the keywords for different countries of earthquake - five keywords comparison at a time - to identify the "earthquake + country name" that have received the highest amount of attention in the sample period from a given country of attention. After identifying this keyword, we compare it with the keywords of other earthquakes and find the Google Trends score of these keywords compared to the one with highest amount of attention. That is, each earthquake receives a Google Trend score of 0 to 100. Following this approach, we obtain the data on the volume of Google searches on our 372 earthquakes of interest from our 18 countries of attention for the period of 2004-2018.

\footnotetext{
${ }^{8}$ Apart from Lebanon, as the volume of Google search in English was higher than the volume of Google searches in Arabic in this country.
} 
Figure 4. 3: IlLUStration of DAta EXtraction from GoOgLe TRENDS

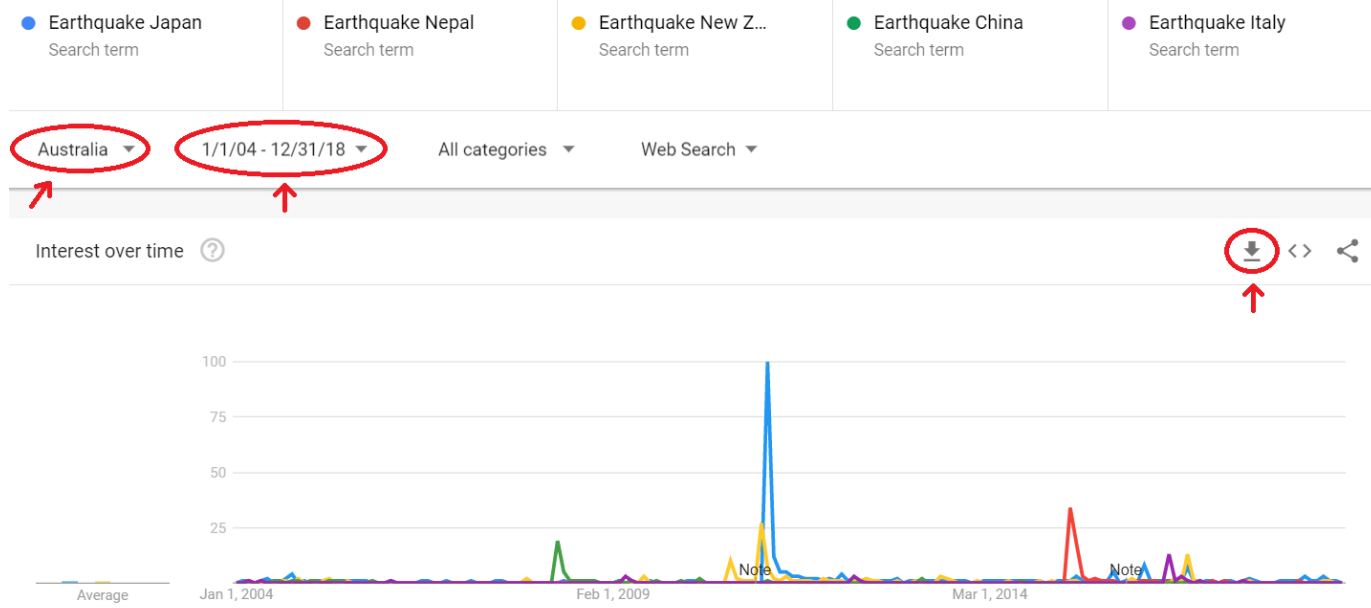

NOTE. - Google Trends data is publicly available on https://trends.google.com/

Figure 4.3 illustrates the process of data extraction from Google Trends dashboard. As shown in Figure 4.3, Google users in Australia paid the most attention to "Earthquake Japan" in March 2011 therefore this earthquake scores 100. This earthquake, also known as earthquake Sendai, generated a tsunami that led to the nuclear accidents in Japan. Compared to this earthquake, "Earthquake Nepal" - the earthquake that hit Nepal in 2015 and killed near 9,000 people - received a Google Trends score of 32 in Australia. This score means that volume of the searches for Nepal earthquake is 32 percent of the volume of searches of the Sendai earthquake. The volume of Google searches on the earthquakes, as our measure of public attention, has a mean of 1.1 out of 100 and standard deviation of 6.3. This distribution shows that the majority of earthquakes receive very little international public attention (see Figure 4.4). 
Figure 4. 4: Distribution of Public Attention

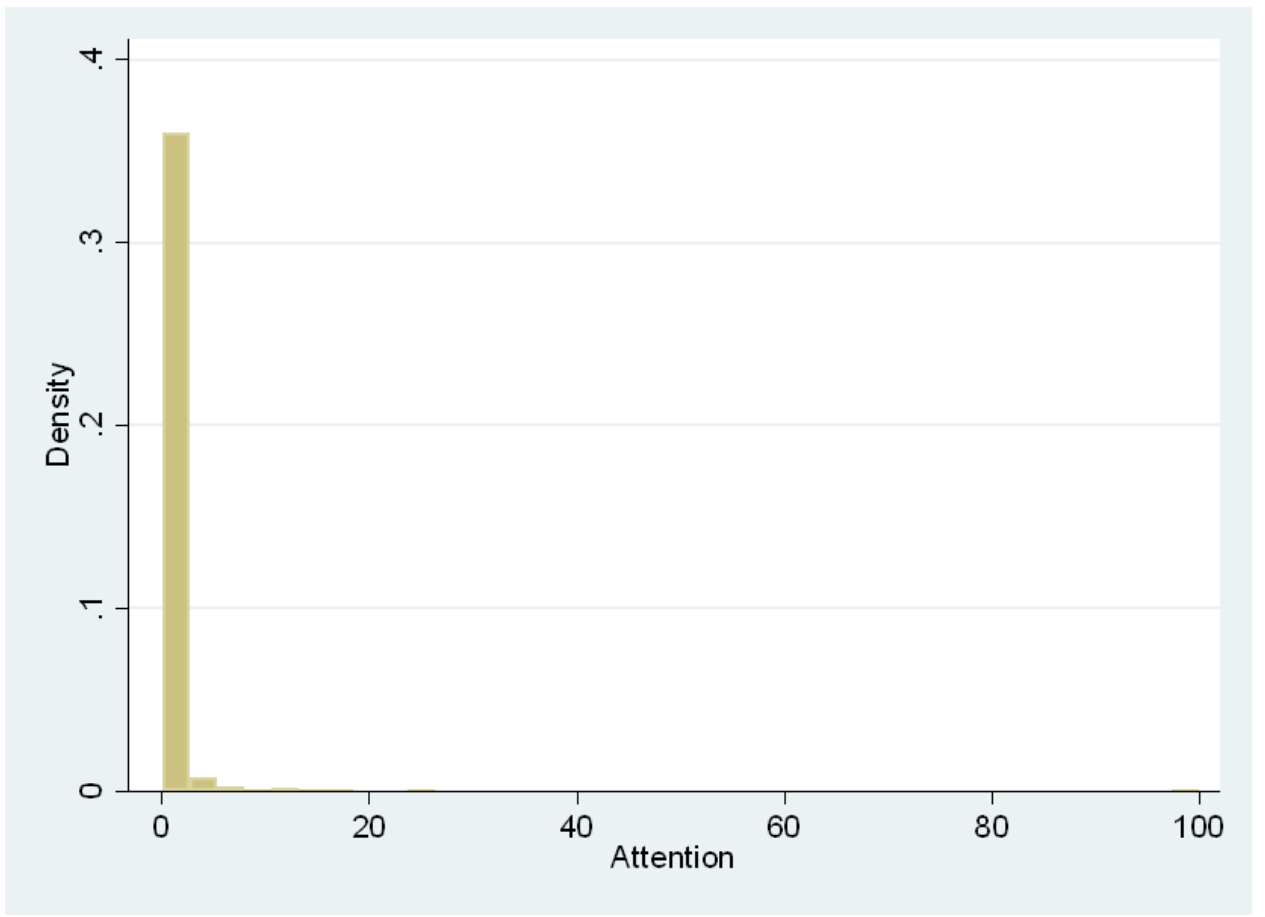

\subsubsection{Control Variables}

Table 4.1 shows summary statistics for our control and main variables. We categorize our control variables into two categories: earthquake characteristics and geographical characteristics. Our earthquake characteristics are the four measures for an earthquake's severity provided in the EM-DAT database: (1) its magnitude of ground shaking in Richter, (2) the number of people it killed; (3) the number of people it affected; and (4) the amount of direct damage it caused (measured in US dollars). On average, the earthquakes included in our sample had a magnitude of 6.34 , killed 1,800 people, affected 262,700 people, and caused a direct damage of $\$ 1,389,000$. Earthquake Sendai that hit Japan in 2011 is the priciest and one of the strongest earthquakes in our sample with a total direct damage of $\$ 210,000,000,000$ and a magnitude of 9.1 Richter. Haiti's 2010 earthquake with a magnitude of 7 Richter caused the highest number of 
casualties, killing 222,570 people, and the 2008 Sichuan earthquake that hit China with a magnitude of 7.9 Richter affected $45,976,596$ people. Our geographical characteristics are whether the countries share border and the geographical distance in kilometer between countries of attention and countries of earthquake. The data on these two variables is available on GeoDist database (CEPII, 2019). We include these 6 control variables in all of our estimations to compare earthquakes that are similarly destructive and similarly close to the country of attention and isolate the predictive power of our explanatory variables of interest. 
TABLE 4. 1: Descriptive STATISTics

\begin{tabular}{|c|c|c|c|c|c|}
\hline & $\begin{array}{l}(1) \\
\mathrm{N}\end{array}$ & $\begin{array}{c}(2) \\
\text { Mean }\end{array}$ & $\begin{array}{l}\text { (3) } \\
\text { Sd }\end{array}$ & $\begin{array}{c}(4) \\
\text { Min }\end{array}$ & $\begin{array}{l}(5) \\
\operatorname{Max}\end{array}$ \\
\hline \multicolumn{6}{|l|}{ Control Variables } \\
\hline \multicolumn{6}{|l|}{ Earthquake Characteristics } \\
\hline Magnitude in Richter & 365 & 6.34 & 1.07 & 4.20 & 9.10 \\
\hline Number of Deaths (in $10,000 \mathrm{ppl}$ ) & 372 & 0.18 & 1.57 & 0 & 22.26 \\
\hline Number of Affected (in $10,000 \mathrm{ppl}$ ) & 372 & 26.27 & 244.1 & 0 & 4,598 \\
\hline Total Damage (in $\$ 100,000,000$ s) & 372 & 13.89 & 120.3 & 0 & 2,100 \\
\hline \multicolumn{6}{|l|}{ Geographical Characteristics } \\
\hline Distance (in 10,000 kms) & 6,678 & 1.01 & 0.44 & 0.02 & 1.98 \\
\hline Common Borders & 6,696 & 0.01 & 0.10 & 0 & 1 \\
\hline \multicolumn{6}{|l|}{ Explanatory Variables } \\
\hline \multicolumn{6}{|l|}{ Social and Cultural Factors } \\
\hline Common Official First Language & 6,696 & 0.13 & 0.33 & 0 & 1 \\
\hline Colonial Tie & 6,678 & 0.02 & 0.12 & 0 & 1 \\
\hline Differences in Share of Christians & 6,696 & 0.476 & 0.30 & 0 & 0.98 \\
\hline Differences in Share of Muslims & 6,696 & 0.402 & 0.41 & 0 & 0.998 \\
\hline Kogut \& Singh Index & 5,218 & 2.24 & 1.53 & 0.02 & 9.21 \\
\hline \multicolumn{6}{|l|}{ Economic Factors } \\
\hline Real GDP per Capita (in $\$ 1,000$ s) & 6,660 & 12.70 & 11.01 & 0.33 & 53.98 \\
\hline Bilateral Trade (in $\$ 1,000,000$ s) & 6,093 & 8,020 & 43,283 & 0 & 480,244 \\
\hline \multicolumn{6}{|l|}{ Political Factors } \\
\hline Closed Autocracy & 6,696 & 0.204 & 0.40 & 0 & 1 \\
\hline Electoral Autocracy & 6,696 & 0.263 & 0.44 & 0 & 1 \\
\hline Electoral Democracy & 6,696 & 0.352 & 0.48 & 0 & 1 \\
\hline Liberal Democracy & 6,696 & 0.164 & 0.37 & 0 & 1 \\
\hline Missing Political Regime & 6,696 & 0.016 & 0.12 & 0 & 1 \\
\hline Freedom in the World & 6,642 & 51.06 & 27.45 & 4 & 99 \\
\hline Corruption Perceptions Index & 6,606 & 3.65 & 1.68 & 0 & 9.50 \\
\hline
\end{tabular}

NOTE. - 'Sd' refers to the standard deviation of the respective variable.

\subsubsection{Social and Cultural Factors}

Our social and cultural factors include shared official first language and colonial tie between the country of attention and the country of earthquake, the differences between the share of Christians \& Muslims in the country of attention and the country of earthquake and the cultural distance between 
them. ${ }^{9}$ We took the data on official first language and colony from the GeoDist database (CEPII, 2017) and the data on religions from the World Religion Database (Todd et al., 2020).

To measure cultural distance between the countries of attention and the countries of earthquake, we use Kogut \& Singh index to measure the cultural distance. Kogut and Singh index uses equation 4.1 to operationalize the four dimensions that Hofstede (1980) uses to describe national culture: power distance, individualism, uncertainty avoidance, and masculinity.

$$
K S I_{j}=\sum_{i=1}^{4}\left\{\left(I_{i j}-I_{i u}\right)^{2} / V_{i}\right\} / 4
$$

$I_{i}$ refers to each of the four original Hofstede dimensions (power distance, uncertainty avoidance, masculinity/femininity, and individualism/collectivism). $j$ and $u$ refer to the two countries they measure their cultural distance. Therefore, $I_{1 j}$ refers to the Hofstede's power distance dimension in country $j$. Equation 4.1 calculates the squared difference of the four dimensions between two countries and divide them by the variance of the dimension, one at a time. The sum of all dimensions is then divided by 4 to get the average difference on the dimensions. The division by first the variance of the dimension and subsequently by 4 means that each dimension is weighted equally, thus the index assumes that each of the four original Hofstede dimensions are equally important. ${ }^{10}$ The index

\footnotetext{
${ }^{9}$ Note that the social and cultural factors mainly aim to measure the social and cultural similarities or differences between two countries. Whereas, the economic and political factors aim to capture the importance of economic and political status of countries.

10 Konara and Mohr (2019) argue that Kogut \& Singh Index is incorrectly specified and captures the squared cultural distance. According to them, the consequences of using this index include, exaggerating large distances over small distance and implications of violating triangular inequality.
} 
is ranged from 0 to 10 , where 10 indicates the farthest cultural distance between two countries. Our sample's mean for Kogut \& Singh index is 2.24.

\subsubsection{Economic Factors}

We include the following economic factors in our analysis: GDP per capita in USD, bilateral trade, and foreign direct investment (FDI). We obtain the data on countries GDP per capita from the World Bank (World Bank, 2019). To obtain the trade relationship between countries, we use Reconciled International Trade data (Shaar, 2019). This database examines the accuracy of reported import and export between two countries and takes the reports from the more reliable source.

The countries of earthquakes' GDP per capita ranges from $\$ 53,980$ to $\$ 330$ with a mean of $\$ 12,700$ (see Table 4.1). These statistics indicate strong skewness in the distribution of GDP per capita among the countries of earthquakes. The same applies to bilateral trade, where it ranges from $\$ 0$ to $\$ 480,244$ million. We therefore take the natural logarithm of countries of earthquakes' GDP per capita and the bilateral trade between countries of attention and earthquakes to control for the impact of extreme values.

\subsubsection{Political Factors}

We include the following factors to examine the political status of countries: countries political system, their political rights and civil liberties, as well as their level of corruption. We use the data on political regimes provided by V-Dem Project (Coppedge et al., 2020). V-Dem Project has created a

They recommend using the correct form of the standardized Euclidean distance formula to investigate the effects of cultural distance. We calculated both measures and found a correlation of 0.98 between the Euclidean measure and Kogut \& Singh index. Therefore, we use the Kogut \& Singh index as it is by far the most used index to measure the cultural distance in the literature. 
dataset that reflects the complexity of democracy as a system of rule rather than presence of elections. Using this data, Lührmann et al., (2018) classify countries into four regime categories: closed autocracy, electoral autocracy, electoral democracy, and liberal democracy. In closed autocracies, there is either no meaningful election or the chief executive is not subjected to elections. Electoral autocracies hold de-facto multiparty elections, but their elections do not meet the democratic standards. Electoral democracies hold de facto fair and multiparty elections and achieve an adequate level of institutional guarantees of democracy. Finally, liberal democracies have effective legislative supervision of the executive and protect the rule of law and individual liberties. Our sample of countries of earthquakes includes $16 \%$ liberal democracies, 35\% electoral democracies, $26 \%$ electoral autocracies, $20 \%$ closed autocracies, and $1.6 \%$ missing political regimes.

To measure political rights and civil liberties, we use the freedom in the world data from Freedom House (Freedom House, 2019). Freedom in the World is Freedom House's flagship annual report, assessing the condition of political rights and civil liberties around the world. It is the most widely read and cited report of its kind. Our sample mean for this measure, which is scaled from 0 to 100 , is 51 . Lastly, to measure corruption, we use the Corruption Perceptions Index (CPI), which is an index published annually by Transparency International. This index ranges from 0 (most corrupt) to 10 (least corrupt) based on the countries perceived level of public sector corruption, as determined by expert assessments and opinion surveys (Transparency International, 2019). Our sample mean for the CPI is 3.65 that is smaller than 4.12, the CPI mean of 180 countries from 2004 to 2018. This indicates a relatively higher level of corruption among the countries of earthquakes compared to the average corruption in the world. To ease the interpretation of the results for freedom in the world and Corruption 
Perception Index, we standardize them to have a mean of 0 and standard deviation of 1 for our estimation sample.

\subsection{Empirical Strategy}

We aim to estimate which factors predict the public attention paid to earthquakes in countries around the world. Our measure of public attention is a variable that counts the volume of Google searches (scaling them from 0 -100) per earthquake and therefore displays the characteristics of a count variable. Count variables have a minimum value of zero and usually follow a Poisson distribution that should be examined with a Poisson model (Cameron \& Trivedi, 2013). However, a Negative Binomial model might fit the count data better in a case of commonly observed over-dispersion in count data (Lord et al., 2005). Over-dispersion refers to having more or less variability in a variable than expected. Our measure of public attention has a mean of 1.1 out of 100 which indicates the possibility of over-dispersion (see Figure 4.4 for the distribution of our measure of public attention). Figure $\mathrm{C} 2$ in Appendix $\mathrm{C}$ shows the existence of over-dispersion by comparing the distribution of our independent variable with the corresponding Negative Binomial distribution and Poisson distribution. As suggested by figure C2, Negative Binominal distribution and therefore Negative Binomial model fits our measure of public attention better than Poisson.

In order to understand the predictors of public attention to earthquakes around the world, we estimate variations of the following empirical model

$$
\text { Attention }_{i c}=\boldsymbol{\beta} X_{i c}^{\prime}+\boldsymbol{\delta} Z_{i c}^{\prime}+u_{i c}
$$

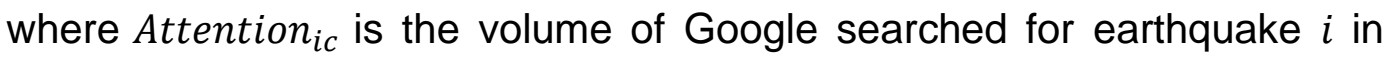
country $c$ (country of attention) which is our measure of public attention. The vector $X_{i c}^{\prime}$, differs by specification and contains the explanatory variables related to each of our three main categories of social and cultural, economic, 
and political factors. $\boldsymbol{\beta}$ is a vector of coefficients for our variables of interest. For example, $\beta_{C D}$ shows the association between the volume of Google searches on an earthquake - that is the public attention the earthquake receives - and the cultural distance between the country of attention and the country of earthquake. This coefficient captures the predicted changes in the log of public attention - holding constant the earthquake and geographic characteristics - for one unit change in the measure of cultural distance (Kogut \& Singh Index is scaled from 0-10). For small values, these log changes are good approximations for percentage changes in attention. Although an earthquake is considered to be an exogenous shock, this coefficient does not have causal interpretation. There might be omitted variables correlated with cultural distance and might drive the observed relationship between cultural distance and attention.

The vector $Z_{i c}^{\prime}$ contains our control variables that are the same for all specifications. We control for cubic polynomials of the earthquake magnitude (measured in Richter), total damage, the number of deaths, and the number of affected. Controlling for these characteristics allows us to consider them as similar shocks regardless of their severity. We also control for the distance between the country of attention and the country of earthquake and whether they share a common border. Moreover, we include country of attention fixed effects and a domestic dummy to account for countries that pay more attention to their domestic earthquakes. Since we observe the attention to the same earthquake from 18 countries, our independent variable of interest varies at the country level. We therefore cluster standard errors at earthquake level. 


\subsection{Results}

\subsubsection{Social and Cultural Factors}

Table 4.2 shows how social and cultural factors predict public attention at an international level. We find that, holding constant the earthquake and geographical characteristics, people pay more attention to earthquakes in countries with which they have similar religion and culture. Our results suggest that the attention paid to earthquakes is positively associated with having a similar religion. People pay less attention to earthquakes in countries with a different religion. However, this association is stronger and statistically significant for differences in the share of Muslims. Our results show that a 10-percentage point increase in the differences between the share of Muslims and Christians in countries of attention and countries of earthquake predicts, respectively, $5.6 \%$ and $0.2 \%$ less public attention to earthquakes. We also find a positive association between the cultural distance between two countries and the attention the earthquakes receive. People pay approximately $7 \%$ less attention to an earthquake when the cultural distance between country of attention and country of earthquake increases by one unit (Kogut \& Singh Index is scaled from 0-10). However, this result is not statistically significant. Moreover, we find a negative correlation between countries having colonial ties and sharing common official language with public attention. People pay, respectively, 23\% and $7 \%$ less attention to earthquakes in countries with which they have/had colonial ties and share a common official language. These results, too, are not statistically significant. The last column of Table 4.2 presents the estimates of an overall model for social and cultural predictors of public attention. While the signs of estimates do not differ from the results of the previous specifications, except for differences in the share of Christians, the magnitudes and significance levels change. Our findings on the role of religion and common official first language are in line with that of Habibi and 
Feld (2018). However, while in our previous paper we find a positive correlation between colonial ties and public attention, our results here show that they are negatively correlated. This difference could be the result of using different estimation models.

Table 4. 2: Social and Cultural Predictors of International Public Attention

Dependent Variable:
Public Attention
Public Attention

Differences in the Share of Christians

Differences in the Share of Muslims

Common Official First Language

Colonial Tie

$\begin{array}{lcccccc}\text { Observations } & 6,534 & 6,534 & 6,534 & 6,534 & 5,100 & 5,100 \\ \text { Earthquake Characteristics } & \text { YES } & \text { YES } & \text { YES } & \text { YES } & \text { YES } & \text { YES } \\ \text { Geographic Characteristics } & \text { YES } & \text { YES } & \text { YES } & \text { YES } & \text { YES } & \text { YES } \\ \text { Pseudo R2 } & 0.255 & 0.260 & 0.255 & 0.255 & 0.259 & 0.265\end{array}$

NOTE. - The dependent variable in all Columns is public attention, which refers to the volume of Google searches scaled from 0-100 calculated by Google Trends. The explanatory variables refer to the social/cultural factors of the country-of-earthquake. All columns are estimated with Negative Binomial regressions that include country-of-attention fixed effect, country of earthquake fixed effects, as well as cubic polynomials of magnitude of the earthquakes, its total damage, number of deaths and injured, country-of-attention and country-of-earthquake distance in $\mathrm{km}$, and a dummy variable, which is equal to 1 if the country-of-attention and the country-of-earthquake share a border. The regressions also include a dummy variable, which is equal to 1 if the earthquake is stricken in the same country that attention is captured from. Robust standard errors in parentheses are clustered at earthquake levels. ${ }^{*} p<0.1,{ }^{* *} p<0.05,{ }^{* * *} p<0.01$. 


\subsubsection{Economic Factors}

Table 4.3 shows the association between economic factors and attention paid to earthquakes worldwide. We find that people pay more attention to earthquakes in richer countries and countries with them they have trade relationship. Our results suggest that a $1 \%$ increase in the GDP per capita of countries of earthquakes is associated with $0.56 \%$ more public attention to earthquakes in these countries. Likewise, $1 \%$ increase in the volume of bilateral trade between the country of attention and the country of earthquake is associated with earthquakes receiving $0.12 \%$ more public attention. The last column of Table 4.3 presents the estimates of an overall model for economic predictors of public attention. The signs of these coefficients do not change in this specification, but the coefficient of bilateral trade reduces in magnitude and becomes statistically insignificant.

Our findings on the role of GDP per capita is in line with the findings in the literature on predictors of public attention to disasters. In our previous paper (Habibi \& Feld 2018) we also found a positive and significant correlation between public attention and GDP per capita. In the literature on predictors of news attention to disasters, Koopmans and Vliegenthart (2010) finding are in line with our findings here. They also find a positive correlation between countries' GDP per capita and level of exports from the countries of attention and the news attention their earthquakes receive. 
Table 4. 3: Economic Predictors of international Public attention

\begin{tabular}{lccc}
\hline $\begin{array}{l}\text { Dependent Variable: } \\
\text { Public Attention }\end{array}$ & $(1)$ & $(2)$ & $(3)$ \\
\hline Natural Logarithm of GDP & & & \\
& $0.56^{* * *}$ & & $0.50^{* * *}$ \\
& $(0.17)$ & & $(0.18)$ \\
Natural Logarithm of Bilateral Trade & & $0.12^{* * *}$ & 0.06 \\
& & $(0.04)$ & $(0.04)$ \\
& & & \\
Observations & & & \\
Earthquake Characteristics & 6,498 & 5,922 & 5,922 \\
Geographic Characteristics & YES & YES & YES \\
Pseudo R2 & YES & YES & YES \\
\hline
\end{tabular}

NOTE. - The dependent variable in all Columns is public attention, which refers to the volume of Google searches scaled from 0-100 calculated by Google Trends. The explanatory variables refer to the economic indicators of the country of earthquake and their trade and financial relationship with the country of attention. All columns are estimated with Negative Binomial regressions that include country of attention fixed effect, country of earthquake fixed effects, as well as cubic polynomials of magnitude of the earthquakes, its total damage, number of deaths and injured, country of attention and country of earthquake distance in $\mathrm{km}$, and a dummy variable, which is equal to 1 if the country of attention and the country of earthquake share a border. The regressions also include a dummy variable, which is equal to 1 if the earthquake is stricken in the same country that attention is captured from. Robust standard errors in parentheses are clustered at earthquake levels. ${ }^{*} p<0.1,{ }^{* *} p<0.05$, ${ }^{\star * \star} p<0.01$.

The findings of Table 4.3 suggest that all countries of attention pay more attention to earthquakes in richer countries and their trading partner countries. Since we have countries with different income levels in our sample of countries of attention, we can further examine these results to see whether this favouring pattern is driven by rich countries only. We compare how GDP per capita and bilateral trade are associated with public attention from countries with different income levels. Our findings show that people from countries with high and upper-middle income levels pay more attention to earthquakes in richer countries and the countries of their trade partners as shown in Figure 4.5. People from countries with lower-middle income level pay more attention to earthquakes in richer countries and less attention to their trade partners. All these findings are statistically significant except the finding on the association between public attention from lowermiddle income countries and bilateral trade. 
Figure 4. 5: Coefficient Plot of Economic Factors for Countries With DIFFERENT INCOME LEVELS

Natural Logarithm of GDP

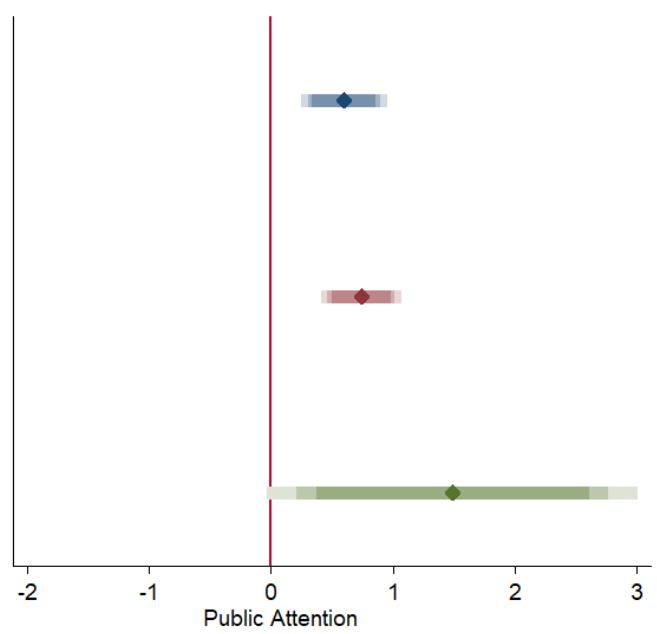

Natural Logarithm of Bilateral Trade

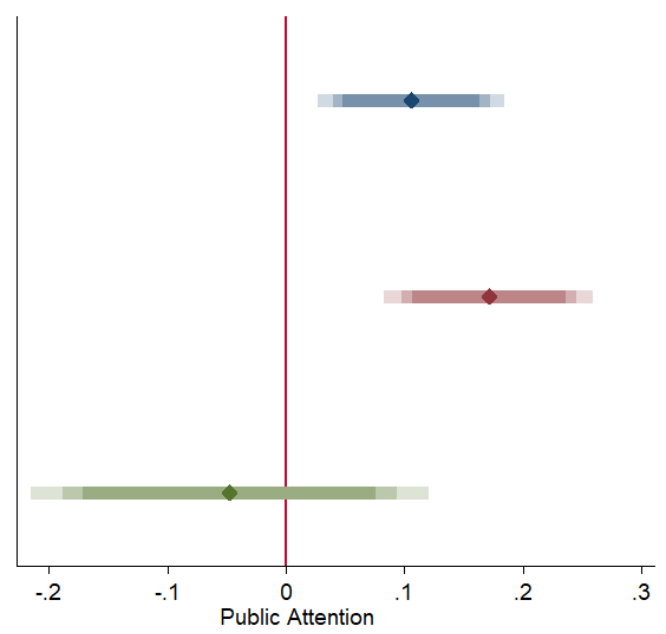

High Income $\quad$ Upper Middle Income $\diamond$ Lower Middle Income

NOTE. - We categorize the countries according to World Bank's categorization of countries income level into high, upper-middle, and lower-middle income countries. The dots show the coefficients of natural logarithm of real GDP per capita and bilateral trade for each of these three groups of countries. All coefficients are estimated with Negative Binomial regressions that include country of attention fixed effect, country of earthquake fixed effects, as well as cubic polynomials of magnitude of the earthquakes, its total damage, number of deaths and injured, country of attention and country of earthquake distance in $\mathrm{km}$, and a dummy variable, which is equal to 1 if the country of attention and the country of earthquake share a border. The regressions also include a dummy variable, which is equal to 1 if the earthquake is stricken in the same country that attention is captured from. Robust standard errors in parentheses are clustered at earthquake levels. The lines are the $85 \%, 90 \%$, and $95 \%$ Confidence Intervals and reflect on the statistical significance of coefficients.

\subsubsection{Political Factors}

Table 4.4 shows how political factors predict attention to earthquakes. Our results suggest that people pay less attention to earthquakes in less democratic countries, countries with more freedom, and less corruption. Earthquakes in countries with a closed and electoral autocracy and electoral democracy regimes receive $359 \%, 184 \%$, and $123 \%$ (1.52, 1.04, and 0.80 log point) less public attention than earthquakes in countries with a liberal democracy regime, respectively. The results are significant at $1 \%$ significance level. These findings are in line with that of Koopmans and Vliegenthart (2010) who find a positive correlation between political freedom 
and news attention to earthquakes. We also find that earthquakes in less corrupt (This index ranges from 0 , most corrupt, to 10, least corrupt) countries receive $38 \%$ ( $0.32 \log$ point) more attention for 1 standard deviation change in Corruption Perceptions Index. Earthquakes in freer countries receive more attention as well, however, this finding is not statistically significant. Column 4 presents the estimations of the political factors in an overall model. The signs and significance levels of all estimates, except for Freedom in the World, stay the same and the magnitudes change slightly.

Table 4. 4: Political Predictors of International Public attention

\begin{tabular}{lllll}
\hline Dependent Variable: & $(1)$ & $(2)$ & $(3)$ & (4) \\
Public Attention & & & &
\end{tabular}

Base Group: Liberal Democracy

$\begin{array}{lc}\text { Closed Autocracy } & -1.52^{\star \star} \\ & (0.19) \\ \text { Electoral Autocracy } & -1.04^{\star \star} \\ \text { Electoral Democracy } & (0.27) \\ & -0.80^{\star \star} \\ & (0.27)\end{array}$

Std. Freedom in the World

Std. Corruption Perceptions Index

Observations

Earthquake Characteristics

Geographic Characteristics

Pseudo R2
6,534

$6,498 \quad 6,462$

YES

YES YES

YES YES YES

6,462

YES

0.276

0.269

YES

NOTE. - The dependent variable in all Columns is public attention, which refers to the volume of Google searches scaled from 0-100 calculated by Google Trends. The explanatory variables refer to the country of earthquake. Liberal Democracy is the base group for the comparison of the coefficients of the remaining three political regimes' (Closed Autocracy, Electoral Autocracy, and Electoral Democracy). All columns are estimated with Negative Binomial regressions that include country-ofattention fixed effect, country of earthquake fixed effects, as well as cubic polynomials of magnitude of the earthquakes, its total damage, number of deaths and injured, country-of-attention and countryof-earthquake distance in $\mathrm{km}$, and a dummy variable, which is equal to 1 if the country-of-attention and the country-of-earthquake share a border. The regressions also include a dummy variable, which is equal to 1 if the earthquake is stricken in the same country that attention is captured from. Robust standard errors in parentheses are clustered at earthquake levels. ${ }^{*} p<0.1,{ }^{* *} p<0.05,{ }^{* *} p<0.01$. 


\subsubsection{Universality of Predictors}

To find out whether our results are similar for the different groups of countries of attention, we first generate three indices for each of our category of predictors and then compare estimates of these indices for our different country groups.

Following Anderson (2008), we create three summary indices that combine the multiple outcomes of each category into a single variable to make the comparison of the three categories of predictors easier. These indices take weighted average of the variables in each category meaning that more important variables receive a higher weight (see Anderson, 2008) and have means of zero and standard deviations of one.

Table 4.5 shows the results of regressing international public attention on these indices. Our findings suggest that for 1 standard deviation increase in social and cultural similarities between country of attention and country of earthquake, earthquakes receive $13 \%$ more public attention. We also estimate that earthquakes receive $82 \%$ and $62 \%$ more public attention, respectively, for 1 standard deviation higher economic factors and 1 standard deviation better political status. These estimates suggest that economic factors are the most important predictors of public attention to earthquakes worldwide, being followed by political status closely. However, these findings might be the result of having better measure for economic factors rather than the superiority of economic factors to other predictors. Given such possibility, we cannot compare these indices and therefore, we only use them to conduct further analysis on the predictors of public attention among different groups of countries in search for universality of predictors. 
Table 4. 5: Social and Cultural Similarities, Economic and Political Status INDICES AND PUBLIC ATTENTION

\begin{tabular}{lcccc}
\hline $\begin{array}{l}\text { Dependent Variable: } \\
\text { Public Attention }\end{array}$ & $(1)$ & $(2)$ & $(3)$ & $(4)$ \\
\hline Std. Social and Cultural Similarities Index & $\begin{array}{c}0.13^{* * *} \\
(0.05)\end{array}$ & & & 0.05 \\
& & $0.60^{* * *}$ & & $(0.06)$ \\
Std. Economic Status Index & & $(0.19)$ & & $0.50^{* *}$ \\
& & & $0.48^{* * *}$ & 0.16 \\
Std. Political Status Index & & & $(0.14)$ & $(0.17)$ \\
& & & & \\
& 6,534 & 6,498 & 6,534 & 6,498 \\
Observations & YES & YES & YES & YES \\
Earthquake Characteristics & YES & YES & YES & YES \\
Geographic Characteristics & 0.255 & 0.278 & 0.268 & 0.280 \\
Pseudo R2 & & & & \\
\hline NOTE
\end{tabular}

NOTE. - The dependent variable in all Columns is public attention, which refers to the volume of Google searches scaled from 0-100 calculated by Google Trends. The explanatory variables are three summary indices that pool the multiple outcomes of our three categories of interest into a single index for each category. All columns are estimated with Negative Binomial regressions that include country-of-attention fixed effect, country of earthquake fixed effects, as well as cubic polynomials of magnitude of the earthquakes, its total damage, number of deaths and injured, country-of-attention and country-of-earthquake distance in $\mathrm{km}$, and a dummy variable, which is equal to 1 if the countryof-attention and the country-of-earthquake share a border. The regressions also include a dummy variable, which is equal to 1 if the earthquake is stricken in the same country that attention is captured from. Robust standard errors in parentheses are clustered at earthquake levels. ${ }^{*} p<0.1,{ }^{* *} p<0.05$, ${ }^{* * *} p<0.01$.

Figure 4.6 shows whether these indices predict attention in the same way in all four groups of countries. The economic factors and political status of countries are universal predictors of public attention and predict receiving more public attention from all four groups. Social and cultural similarities, however, predict more public attention from Western and Latin American countries and less public attention from Arab and Sub-Saharan African countries. Therefore, since social and cultural similarities predict public attention in different directions for different groups of countries, they cannot be considered as universal predictors of public attention. 
Figure 4. 6: Coefficient Plot of Social and Cultural Similarities, Economic FACTORS, AND POLITICAL STATUS INDICES COMPARISON
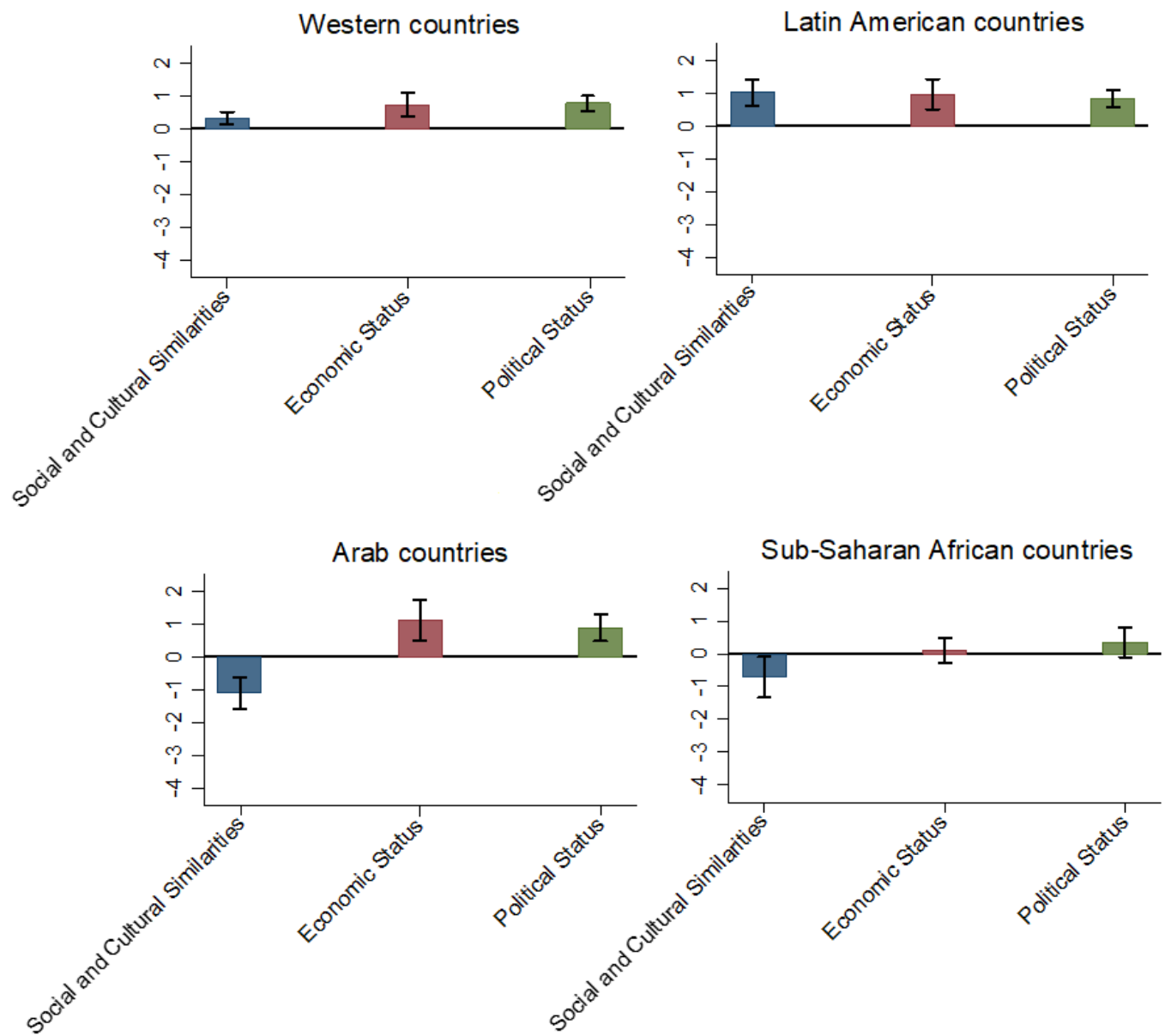

NOTE. - The cubes show the coefficients of three summary indices that combine the multiple outcomes of each category into a single variable. All coefficients are estimated with Negative Binomial regressions that include country of attention fixed effect, country of earthquake fixed effects, as well as cubic polynomials of earthquakes total damage (except for Sub-Saharan African countries), magnitude, number of deaths and injured, country of attention and country of earthquake distance in $\mathrm{km}$, and a dummy variable, which is equal to 1 if the country of attention and the country of earthquake share a border. The regressions also include a dummy variable, which is equal to 1 if the earthquake is stricken in the same country that attention is captured from. Since the Poisson regression for the Sub-Saharan African group would not run (returning not negative semidefinite Hessian), perhaps due to the high percentage of zeroes in this sub-sample, we had to exclude total damage of earthquakes and the cubic polynomials of earthquake characteristics from our control variables to simplify the $D$ matrix and therefore Hessian Matrix. As a robustness check for these estimates, we estimated an OLS regression with all control variables (see Figure $\mathrm{C} 1$ in the Appendix $\mathrm{C}$ ). Robust standard errors in parentheses are clustered at earthquake levels. The lines are the $85 \%, 90 \%$, and $95 \%$ Confidence Intervals and reflect on the statistical significance of coefficients.

The previous studies that examine the predictors of public and news attention to disasters solely focus on Western countries and do not examine the universality of their findings. Nevertheless, there is one study that 
investigates the news attention to other countries and examines the universality of news attention predictors ( $\mathrm{Wu}, 2000)$. This study, however, only finds trade and presence of international news agencies to be the universal predictors of international news attention. The possible explanations for the differences between our findings are; i) the differences between public and news attention. Where we examine the predictors of public attention, Wu examines the predictors of news attention, ii) focusing on different topics. Where we solely focus on attention paid to disasters, $\mathrm{Wu}$ focuses on news attention paid to a country in general, and iii) using different estimation models. Where we use a Poisson model, Wu uses a linear model to estimate the predictors of a count variable, which can compute smaller coefficients due to relying on mean effects rather than the effect on the entire distribution of outcomes.

\subsection{Conclusion}

We have investigated the predictors of public attention to earthquakes through regressing the volume of Google searches on the keywords related to the earthquakes from 18 countries on 11 social, cultural, economic, and political predictors. Our findings show that countries' social and cultural similarities, economic factors and political status predict the international public attention to an earthquake. People pay more attention to earthquakes in countries with which they share religion and culture. These findings are intuitive and in line with our expectations. We also show that earthquakes in richer countries, trading partners, more democratic countries, freer countries, and less corrupt countries receive more international public attention. These findings are also in line with our expectations.

We also show that two sets of predictors are universal by comparing the predictors among different groups of countries. The economic and political factors predict public attention in the same way in all four groups of countries. 
In contrary, social and cultural similarities predict more public attention from Western and Latin American countries and less public attention from Arab and Sub-Saharan African countries and therefore cannot be considered as universal predictors of public attention. Why social and cultural similarities act as counter supportive factors among some groups of countries and vice versa among others is an interesting question that raises from our findings and requires further research.

Finally, we compare our findings with the findings on the predictors of news attention. While we examine a wider range of predictors here, most of our predictors have been already examined in the literature on predictors of news attention. Comparing our findings with the findings of news attention literature show that the sign of public attention and news attention predictors are mainly the same, however, the magnitudes and statistical powers differ. This suggests that in the concept of international attention to disasters, predictors of news attention are similar to predictors of public attention. 


\section{Appendix C}

\section{Figure C 1: Coefficient Plot of Social and Cultural Similarities, Economic} and Political Status Indices Comparison

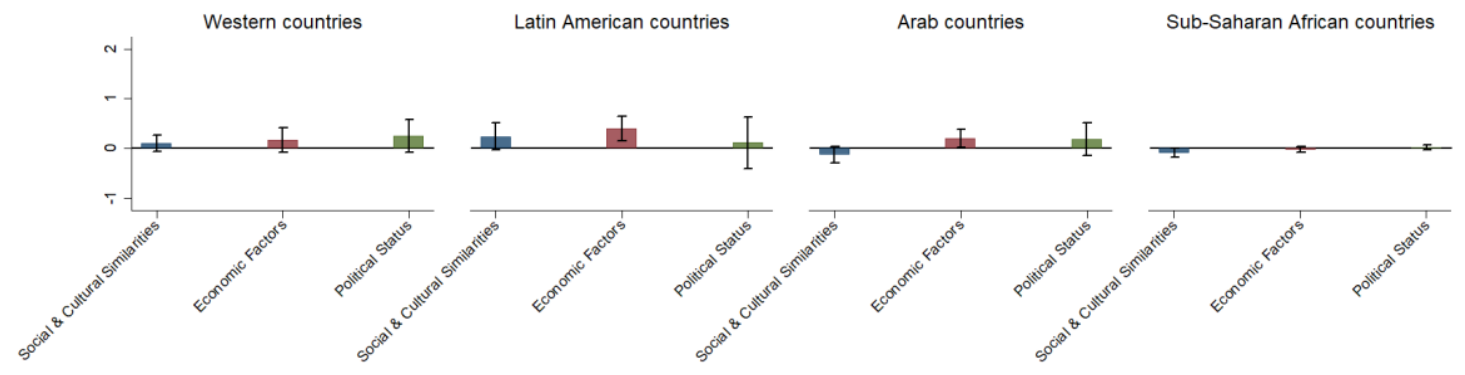

NOTE. - The cubes show the coefficients of three summary indices that combine the multiple outcomes of each category into a single variable. All coefficients are estimated with OLS regressions that include country of attention fixed effect, country of earthquake fixed effects, as well as cubic polynomials of magnitude of the earthquakes, its total damage, number of deaths and injured, country of attention and country of earthquake distance in $\mathrm{km}$, and a dummy variable, which is equal to 1 if the country of attention and the country of earthquake share a border. The regressions also include a dummy variable, which is equal to 1 if the earthquake is stricken in the same country that attention is captured from. Robust standard errors in parentheses are clustered at earthquake levels. The lines are the $85 \%, 90 \%$, and $95 \%$ Confidence Intervals and reflect on the statistical significance of coefficients. 
FIGURE C 2: COMPARISION OF THE DISTRIBUTION OF PUBLIC ATTENTION VARIABLE With Negative Binomial and PoIsSon distributions

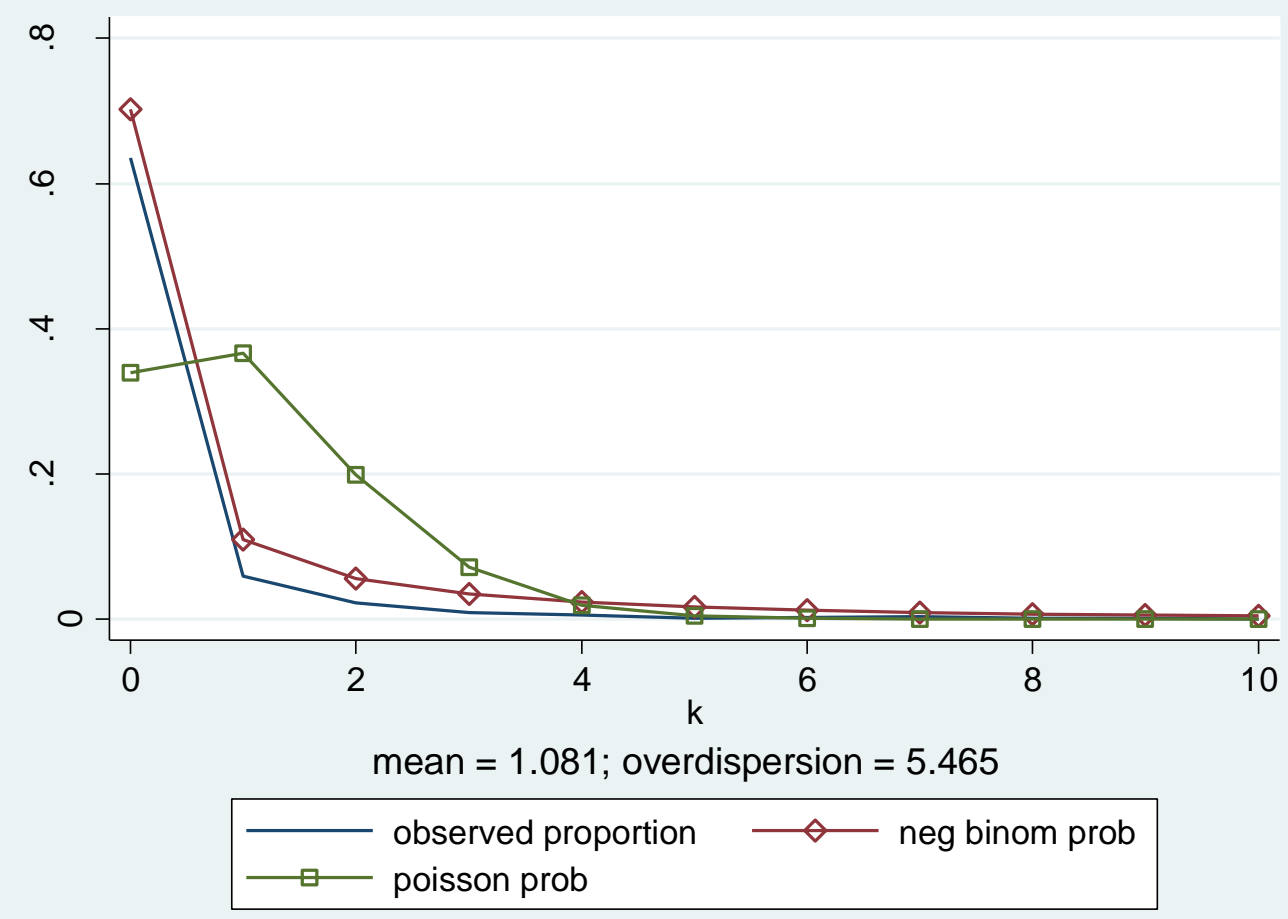




\section{BIBLIOGRAPHY}

Anderson, M. L. (2008). Multiple inference and gender differences in the effects of early intervention: A reevaluation of the Abecedarian, Perry Preschool, and Early Training Projects. Journal of the American statistical Association, 103(484), 1481-1495.

Ashenfelter, O. C., \& Card, D. (1984). Using the longitudinal structure of earnings to estimate the effect of training programs (No. w1489). National Bureau of Economic Research.

Becerra, O., Cavallo, E., \& Noy, I. (2014). Foreign aid in the aftermath of large natural disasters. Review of Development Economics, 18(3), 445460.

Becker, J. S., Paton, D., Johnston, D. M., Ronan, K. R., \& McClure, J. (2017). The role of prior experience in informing and motivating earthquake preparedness. International Journal of Disaster Risk Reduction, 22, 179-193.

Berglez, P., \& Lidskog, R. (2019). Foreign, domestic, and cultural factors in climate change reporting: Swedish media's coverage of wildfires in three continents. Environmental Communication, 13(3), 381-394.

Bertrand, M., Duflo, E., \& Mullainathan, S. (2004). How much should we trust differences-in-differences estimates?. The Quarterly Journal of Economics, 119(1), 249-275.

Callaway, B., \& Sant'Anna, P. H. (2019). Difference-in-differences with multiple time periods. Available at SSRN 3148250. 
Cameron, A. C., \& Trivedi, P. K. (2013). Regression analysis of count data (Vol. 53). Cambridge university press.

Cavanagh, P., Lang, C., Li, X., Miao, H., \& Ryder, J. D. (2014). Searching for the determinants of climate change interest. Geography Journal, 2014. CEPII - Centre d'Études Prospectives et d'Informations Internationales (2017) GeoDist database. [Online]. Available: http://www.cepii.fr/anglaisgraph/bdd/distances.htm [Accessed: 2017 September].

CEPII - Centre d'Études Prospectives et d'Informations Internationales (2019) GeoDist database. [Online]. Available: http://www.cepii.fr/anglaisgraph/bdd/distances.htm [Accessed: 2019 November].

Chang, T. K., Shoemaker, P. J., \& Brendlinger, N. (1987). Determinants of international news coverage in the US media. Communication Research, 14(4), 396-414.

Choi, D., Gao, Z., \& Jiang, W. (2020). Attention to global warming. The Review of Financial Studies, 33(3), 1112-1145.

Coppedge et al. (2020). "V-Dem [Country-Year/Country-Date] Dataset v10". Varieties of Democracy (V-Dem) Project. https://doi.org/10.23696/vdemds20.

Eisensee, T., \& Strömberg, D. (2007). News droughts, news floods, and US disaster relief. The Quarterly Journal of Economics, 122(2), 693-728. 
EM-DAT (2019) Disaster profile for earthquakes. EM-DAT: international disaster database. http://www.em-dat.net/ disaster/profiles.php. Accessed Feb 2019

Franks, S. (2006). The CARMA report: western media coverage of humanitarian disasters. The Political Quarterly, 77(2), 281-284.

Freedom House, Freedom in the World (2019) - United States, 16 January 2019, available at: https://freedomhouse.org/report/freedomworld/2020/leaderless-struggle-democracy

Ginsberg, J., Mohebbi, M. H., Patel, R. S., Brammer, L., Smolinski, M. S., \& Brilliant, L. (2009). Detecting influenza epidemics using search engine query data. Nature, 457(7232), 1012-1014.

Global Bilateral Migration Database, World Bank Group Özden, Ç., Parsons, C. R., Schiff, M., \& Walmsley, T. L. (2011). Where on earth is everybody? The evolution of global bilateral migration 1960-2000. The World Bank Economic Review, 25(1), 12-56.

Goeschl, T., \& Managi, S. (2019). Public in-kind relief and private selfinsurance. Economics of Disasters and Climate Change, 3(1), 3-21.

Google (2017) Google Trends. [Online]. Available: http://www.google.com/trends/. [Accessed 2017 June]

Grasland, C. (2020). International news flow theory revisited through a space-time interaction model: Application to a sample of 320,000 international news stories published through RSS flows by 31 daily newspapers in 2015. International Communication Gazette, 82(3), 231259. 
Habibi, H., \& Feld, J. (2018). Do People Pay More Attention to Earthquakes in Western Countries?. In 2nd International Conference on Advanced Research Methods and Analytics (CARMA 2018). Proceedings.

Hoffman, A. J., \& Ocasio, W. (2001). Not all events are attended equally: Toward a middle-range theory of industry attention to external events. Organization science, 12(4), 414-434.

Hoffmann, R., \& Muttarak, R. (2015). A tale of disaster experience in two countries: Does education promote disaster preparedness in the Philippines and Thailand (No. 9/2015). Vienna Institute of Demography Working Papers.

Hofstede, G. (1980). Motivation, leadership, and organization: do American theories apply abroad?. Organizational dynamics, 9(1), 42-63.

Huntington, S. P. (2000). The clash of civilizations?. In Culture and politics (pp. 99-118). Palgrave Macmillan, New York.

Johnson, T. M., \& Zurlo, G. A. (2007). World christian database. Leiden/Boston: Brill.

Kariel, H. G., \& Rosenvall, L. A. (1984). Factors influencing international news flow. Journalism Quarterly, 61(3), 509-666.

Kim, K., \& Barnett, G. A. (1996). The determinants of international news flow: A network analysis. Communication Research, 23(3), 323-352.

Kirschenbaum, A. A., Rapaport, C., \& Canetti, D. (2017). The impact of information sources on earthquake preparedness. International Journal of Disaster Risk Reduction, 21, 99-109. 
Konara, P., \& Mohr, A. (2019). Why we should stop using the Kogut and Singh Index. Management International Review, 59(3), 335-354.

Koopmans, R., \& Vliegenthart, R. (2010). Media attention as the outcome of a diffusion process-A theoretical framework and cross-national evidence on earthquake coverage. European Sociological Review, 27(5), 636-653.

Kwak, H., An, J., Salminen, J., Jung, S. G., \& Jansen, B. J. (2018). What we read, what we search: Media attention and public attention among 193 countries. In Proceedings of the 2018 World Wide Web Conference (pp. 893-902).

Lee, M. J., \& Kang, C. (2006). Identification for difference in differences with cross-section and panel data. Economics letters, 92(2), 270-276.

Lord, D., Washington, S. P., \& Ivan, J. N. (2005). Poisson, Poissongamma and zero-inflated regression models of motor vehicle crashes: balancing statistical fit and theory. Accident Analysis \& Prevention, 37(1), 35-46.

Lührmann, A., Tannenberg, M., \& Lindberg, S. I. (2018). Regimes of the World (RoW): Opening New Avenues for the Comparative Study of Political Regimes. Politics \& Governance, 6(1).

Meyer, R., \& Kunreuther, H. (2017). The ostrich paradox: why we underprepare for disasters. Wharton Digital Press.

Ministry of Civil Defence and Emergency Management (2016). Disaster Preparedness Survey.

http://www.civildefence.govt.nz/assets/Uploads/public-education/CivilDefence-Report-170ct2016.pdf 
Mulilis, J. P., Duval, T. S., \& Lippa, R. (1990). The effects of a large destructive local earthquake on earthquake preparedness as assessed by an earthquake preparedness scale. Natural hazards, 3(4), 357-371.

National Geophysical Data Center / World Data Service (NGDC/WDS): Global Significant Earthquake Database. National Geophysical Data Center, NOAA. doi:10.7289/V5TD9V7K [Accessed 2017 June]

Newell, P. (2006). Climate for change: Non-state actors and the global politics of the greenhouse. Cambridge University Press.

Newig, J. (2004). Public attention, political action: the example of environmental regulation. Rationality and Society, 16(2), 149-190.

New Zealand Red Cross. (2019). Emergency preparedness. https://www.redcross.org.nz/what-we-do/in-new-zealand/disastermanagement/looking-after-yourself/emergency-preparedness/

Ng, S. I., Lee, J. A., \& Soutar, G. N. (2007). Are Hofstede's and Schwartz's value frameworks congruent?. International marketing review.

Nghiem, L. T., Papworth, S. K., Lim, F. K., \& Carrasco, L. R. (2016). Analysis of the capacity of Google Trends to measure interest in conservation topics and the role of online news. PloS one, 11(3).

Nguyen, L. H., Shen, H., Ershoff, D., Afifi, A. A., \& Bourque, L. B. (2006). Exploring the causal relationship between exposure to the 1994 Northridge earthquake and pre-and post-earthquake preparedness activities. Earthquake Spectra, 22(3), 569-587.

Nnaemeka, T., \& Richstad, J. (1981). Internal controls and foreign news coverage: Pacific press systems. Communication Research, 8(1), 97-135. 
Nossek, H. (2004). Our news and their news: The role of national identity in the coverage of foreign news. Journalism, 5(3), 343-368.

Onuma, H., Shin, K. J., \& Managi, S. (2017). Household preparedness for natural disasters: Impact of disaster experience and implications for future disaster risks in Japan. International Journal of Disaster Risk Reduction, 21, 148-158.

Petkova, E. P., Schlegelmilch, J., Sury, J., Chandler, T. E., Duran Herrera, C., Bhaskar, S., ... \& Redlener, I. E. (2016). The American preparedness project Where the US public stands in 2015.

Russell, L. A., Goltz, J. D., \& Bourque, L. B. (1995). Preparedness and hazard mitigation actions before and after two earthquakes. Environment and Behavior, 27(6), 744-770.

Chang TK, Shoemaker P and Brendlinger N (1987) Determinants of international news coverage in the US media. Communication Research, 14(4), 396-414.

Schäfer, M. S., Ivanova, A., \& Schmidt, A. (2014). What drives media attention for climate change? Explaining issue attention in Australian, German and Indian print media from 1996 to 2010. International Communication Gazette, 76(2), 152-176.

Schmidt, A., Ivanova, A., \& Schäfer, M. S. (2013). Media attention for climate change around the world: A comparative analysis of newspaper coverage in 27 countries. Global Environmental Change, 23(5), 12331248.

Long, J. (1997). Regression models for categorical and limited dependent variables. Advanced quantitative techniques in the social sciences, 7 . 
Segev, E. (2015). Visible and invisible countries: News flow theory revised. Journalism, 16(3), 412-428.

Shaar, K. (2019). Reconciling international trade data.

Shenhav, S. R., Rahat, G., \& Sheafer, T. (2012). Testing the languagepower assumption of critical discourse analysis: The Case of Israel's legislative discourse. Canadian Journal of Political Science/Revue canadienne de science politique, 45(1), 207-222.

Simon, A. F. (1997). Television news and international earthquake relief. Journal of Communication, 47(3), 82-93.

Statistics New Zealand. (2013). Area unit 2013. Retrieved December 2, 2018, from https://datafinder.stats.govt.nz/layer/25743-area-unit-2013/

Statistics New Zealand 2013 Census (2013). http://archive.stats.govt.nz/Census/2013-census/profile-and-summaryreports

Statistics New Zealand. (2017). Area unit population projections. http://archive.stats.govt.nz/browse for stats/population/estimates and projections/area-unit-population-projections.aspx

Statistics New Zealand. (2019). New Zealand General Social Survey. http://archive.stats.govt.nz/browse for stats/people and communities/ well-being/nzgss-info-releases.aspx

Stats, S. G. (2017). StatCounter Global Stats.

Stats, S. G. (2020). StatCounter Global Stats. 
The World Bank, Economy \& Growth Indicators (2019). GDP per capita. Retrieved from https://data. worldbank.org/indicator/NY.GDP.PCAP.KD

Todd M. Johnson and Brian J. Grim, eds. World Religion Database (Leiden/Boston: Brill, 2020)

Transparency International (2019), Corruption Perceptions Index available at: https://www.transparency.org/cpi2019

Van Belle, D. A. (2000). New York Times and network TV news coverage of foreign disasters: The significance of the insignificant variables. Journalism \& Mass Communication Quarterly, 77(1), 50-70.

U.S. Geological Survey, ShakeMap (2018). Earthquake Ground Motion and Shaking Intensity Maps: U.S. Geological Survey. http://earthquake.usgs.gov/shakemap

WCD - World Christian Database (2017) Country / Religion Database. [Online]. Available: http://www.worldchristiandatabase.org/wcd/ [Accessed: 2017 October].

Wood, A., Noy, I., \& Parker, M. (2016). The Canterbury rebuild five years on from the Christchurch earthquake. The Reserve Bank of New Zealand Bulletin, 79(3), 3.

Wood, H. O., \& Neumann, F. (1931). Modified Mercalli intensity scale of 1931. Bulletin of the Seismological Society of America, 21(4), 277-283.

Wu, H. D. (2000). Systemic determinants of international news coverage: A comparison of 38 countries. Journal of communication, 50(2), 110-130. 
Wu, H. D. (2007). A brave new world for international news? Exploring the determinants of the coverage of foreign news on US websites. International Communication Gazette, 69(6), 539-551. 